\title{
On the Microstructure and Strengthening Mechanism in Oxide Dispersion-Strengthened 316 Steel: A Coordinated Electron Microscopy, Atom Probe Tomography and In-situ Synchrotron Tensile Investigation
}

\author{
Yinbin Miao ${ }^{\mathrm{a}, *}$, Kun Mo ${ }^{\mathrm{b}}$, Zhangjian Zhou ${ }^{\mathrm{c}}$, Xiang Liu ${ }^{\mathrm{a}}$, Kuan-Che Lan ${ }^{\mathrm{a}}$, Guangming Zhang ${ }^{\mathrm{a}, \mathrm{c}}$, \\ Michael K. Miller ${ }^{\mathrm{d}}$, Kathy A. Powers ${ }^{\mathrm{d}}$, Zhi-Gang Mei ${ }^{\mathrm{b}}$, Jun-Sang Park ${ }^{\mathrm{e}}$, Jonathan Almere, \\ James F. Stubbins ${ }^{\mathrm{a}}$ \\ ${ }^{a}$ Department of Nuclear, Plasma, and Radiological Engineering, University of Illinois at Urbana-Champaign, Urbana, \\ IL 61801, USA \\ ${ }^{b}$ Nuclear Engineering Division, Argonne National Laboratory, Lemont, IL 60439, USA \\ ${ }^{c}$ Department of Material Science and Engineering, University of Science and Technology Beijing, Beijing 100084, \\ China \\ ${ }^{d}$ Center for Nanophase Materials Sciences, Oak Ridge National Laboratory, Oak Ridge, TN 37831, USA \\ ${ }^{e}$ Advanced Photon Source, Argonne National Laboratory, Lemont, IL 60439, USA
}

\begin{abstract}
An oxide dispersion-strengthened (ODS) 316 steel was developed to simultaneously provide the advantages of ODS steels in mechanical strength and radiation tolerance as well as the excellence of austenitic steels in creep performance and corrosion resistance. The precipitate phases within the austenite matrix were identified by the combined techniques of atom probe tomography (APT), scanning transmission electron microscopy equipped with electron dispersive X-ray spectroscopy (STEM-EDS), and synchrotron wide-angle and small-angle X-ray scattering (WAXS and SAXS). Coarse TiN, hexagonal $\mathrm{YAlO}_{3}$ and orthorhombic $\mathrm{YAlO}_{3}$ precipitates were found along with fine Y-Ti-O nanoparticles. In-situ WAXS experiments were performed at room and elevated temperatures to examine the size effect on the load partitioning phenomenon for TiN, hexagonal $\mathrm{YAlO}_{3}$ and $\mathrm{Y}_{2} \mathrm{Ti}_{2} \mathrm{O}_{7}$ phases. In addition, the dislocation density evolution throughout the tensile tests was analyzed by the modified Williamson-Hall method and confirmed by transmission electron microscopy (TEM) observations, revealing the difference in plasticity at various temperatures.
\end{abstract}

Keywords: oxide dispersion-strengthened steel, atom probe tomography, scanning transmission electron microscopy, synchrotron X-ray scattering

\section{Introduction}

Materials challenges are among the most crucial factors that limit the advances of nuclear technology, since materials used in nuclear reactors are required to persistently maintain their

\footnotetext{
*Address: 216 Talbot Laboratory, 104 South Wright Street, Urbana, IL 61801 Tel: 217-607-6294 Email:
} miao2@illinois.edu 
performance in extreme environments including elevated temperature, aggressive coolant, high pressure, and intense neutron flux. The development of Generation IV nuclear fission reactors is facing significant difficulties in the selection of structural materials[1]. The novel designs of these nuclear reactors usually involve higher operating temperatures and advanced coolants, which demand excellent high temperature mechanical performance and corrosion resistance of the structural materials involved. The development of the supercritical water reactor, the only Generation IV design to employ water coolant, is facing challenges in the search for structural materials, especially in the fuel cladding material. A series of advanced materials, including austenite stainless steels, reduced activation ferritic/martensitic alloys (RAFM), ferritic/martensitic (F/M) oxide dispersion-strengthened (ODS) steels, nickel-based advanced alloys and refractory alloys, have been investigated as prospective candidates[2, 3, 4, 5]. Recently, a number of F/M ODS steels have been developed and examined for several key properties necessary for the applications in nuclear reactors[6, 7]. However, the F/M phase of Fe-based alloys, with its low $\mathrm{Cr}$ content of less than $9 \mathrm{wt} \%$, has intrinsically poor corrosion resistance, which limits its applications in fuel cladding materials, especially in the supercritical water environment. A higher $\mathrm{Cr}$ content may improve the corrosion performance[8], but at the expense of introducing $\alpha-\alpha^{\prime}$ phase separation during thermal aging enhanced by neutron irradiation[9, 10]. These Cr-enriched $\alpha^{\prime}$ precipitates embrittle the material, degrading its ductility and toughness.

On the other hand, the advantages of austenitic stainless steels include their excellent creep performance and corrosion resistance, making them competitive candidates for fuel cladding materials. In addition, austenite is the stable phase at high temperatures, assuring reliability in accident conditions. Unfortunately, conventional austenitic steels suffer from severe radiation swelling[11], and are of relatively low mechanical strength when compared to ferritic steels. Both of these disadvantages limit the application of austenitic steels to advanced reactors. Mechanical alloying followed by a series of heat treatment and thermal processing procedures introduces into the steel matrix a dense and dispersed distribution of ultra-fine oxide nanoparticles that are quite stable at high temperatures[12] and under high irradiation conditions[13, 14]. Previous studies of the ferritic ODS steels clearly show that the ultra-fine oxide nanoparticles as well as the reduced grain size enhance the mechanical strength by pinning dislocations[15]. In addition, the extra interfaces created by the nanoparticles can act as sinks for point defects generated by irradiation and even attract helium atoms produced by (n, $\alpha)$ reactions $[16,17,18,19]$. Thus, both the irradiation-induced dislocation loop evolution and radiation swelling can be suppressed. Therefore, oxide nanoparticles, coupled with a finer grain structure is expected to give austenitic steels excellent radiation tolerance and mechanical strength with marginal compromise in the intrinsic advantages of austenitic steels. A series of ODS austenitic steels have been developed and proven to display the excellent conditions mentioned above[20, 21, 22, 23, 24, 25].

The characteristics of the oxide nanoparticles, including their size distribution, chemical composition, morphology, orientation relationship, and interaction mechanisms with the dislocations, are crucial properties that influence the performance of the ODS austenitic steels as nuclear structural materials. Scanning transmission electron microscopy (STEM), equipped with a high angle annualar dark field (HAADF) detector, is capable of yielding image contrast that is proportional to the square of the atomic numbers $\left(Z^{2}\right)$ of the materials, and is therefore called Z-contrast. This technique can be used to identify the precipitates in ODS steels. More importantly, embedded with the spectroscopic capabilities of electron dispersive X-ray spectroscopy (EDS) and electron energy loss spectroscopy (EELS), STEM is capable of providing additional chemical information of these precipitates[26, 27, 28]. However, the resolution limitation of conventional STEM restricts its application to the investigation of nanoparticles greater than $3 \mathrm{~nm}$ in diameter. 
Atom probe tomography (APT), which has been developed in the past decades based on the previous success of atom probe field ion microscopy (APFIM), is able to collect over $37 \%$ of the atoms in a sample containing up to billions of atoms by identifying information on the atom types and reconstructing the atom positions based on a high efficiency position sensitive time-of-flight (ToF) mass spectroscopy detector. Therefore, this technique is an ideal complement to STEM in examining nanoparticles smaller than $3 \mathrm{~nm}[29]$. Although the development of advanced APT algorithms recently realized the reconstruction of the lattice structure by means of 3D Hough transformations[30], it is currently still unlikely that the crystal structure of the nanoscale precipitates and their orientation relationships with the matrix can be distinguished, especially when the laser mode has to be adopted due to the poor thermal and electric conductivities of the specimens[24]. STEM is capable of providing sub- $\AA$, or atomic resolution with a spherical aberration $\left(C_{s}\right)$ correction, and has already been used to explore the morphology of the oxide nanoparticles in ODS steels[31]. However, the results are not explicit and therefore require interpretation using image simulation techniques. On the contrary, high-resolution transmission electron microscopy (HRTEM) provides phase contrast images with atomic resolution, and has been successfully applied to crystal structure and orientation relationship analyses of ODS steels[32, $33,34,23,24]$.

With ultra-high energy X-rays of high intensity, synchrotron light sources offer the possibility of collecting scattering information from phases with marginal volume fractions that are unlikely to be captured by conventional X-ray sources[24]. Wide-angle X-ray scattering (WAXS) can produce diffraction information of precipitates for phase identification, whereas small-angle X-ray scattering (SAXS) can be used to analyze the size distribution of the ultra-fine precipitates[35].

The oxide nanoparticles in ODS steels enhance the mechanical strength of the material by interacting with dislocations and suppressing grain growth. The nanoparticle-dislocation interactions result in pileups of dislocations on the nanoparticles. With dislocations restraining them, the precipitates have larger lattice strains than those of the matrix and therefore can bear much more load during plastic deformation. This load partitioning phenomenon is the foundation of precipitate-strengthening mechanism. Being capable of measuring the lattice spacing of precipitate phases, WAXS investigation can be utilized to monitor the lattice strain evolution of the precipitates during tensile tests. Hence, in-situ WAXS tensile experiments are powerful tools to explore the load partitioning phenomenon. In fact, this technique has been employed to investigate the strengthening mechanisms in a variety of precipitate-strengthened materials including ferrite or martensite steels[36, 37, 38, 39], Ni-based superalloys[40], and ODS steels[7, 41]. The success of these previous applications ensures the success of using this technique to investigate the contributions of the oxide nanoparticles to the mechanical strength enhancement of ODS 316 steel.

Another benefit is that the diffraction peaks in WAXS contain information on the grain size, dislocation density, and stacking fault/twinning portions within the phases of interest. Ungár developed a method to assess these quantities based on the diffraction peak broadening, which is call the modified Williamson-Hall (W-H) method[42]. With in-situ experiment capabilities, this analysis technique can be applied to monitor the real-time alterations of microstructures within materials.

In this study, a coordinated combination of advanced microstructure characterization techniques were systematically utilized to retrieve comprehensive information including the size distribution, volume fraction, chemical composition, and crystal structure of all the precipitate phases, especially the oxide nanoparticles, existing in a recently developed ODS 316 stainless steel[43]. In-situ synchrotron tensile investigations were then performed for the ODS 316 steel, allowing the 
load partitioning phenomenon as well as the dislocation density evolution during the plastic deformation to be analyzed to help reveal the strengthening mechanism of austenitic ODS steels. The knowledge obtained in this research effort will expand the understanding of the origin of the outstanding mechanical strength of austenitic ODS steels, permitting examination of the feasibility of using austenite ODS steels for fuel cladding in future advanced reactor systems.

\section{Description of Experiments}

\subsection{Investigated Material}

The ODS stainless steel $316(\mathrm{LN})$ investigated in this study has the composition listed in Table 1. The base material powders were mechanically alloyed in an argon atmosphere using a planetary ball mill at $300 \mathrm{rpm}$ with a ball-to-powder ratio of 5:1 for 30 hours. The milled powders were then degassed, sealed, and consolidated by hot isostatic pressing (HIP) under a pressure of $100 \mathrm{MPa}$ at $1150^{\circ} \mathrm{C}$ for 3 hours. The manufacturer reported that the ODS 316 steel has an average grain size of approximately $250 \mathrm{~nm}$ and a dense distribution of oxide nanoparticles[43].

Table 1: Chemical composition (wt\%) of the ODS 316 steel investigated in this study

\begin{tabular}{cccccccccccc}
\hline $\mathrm{Fe}$ & $\mathrm{Cr}$ & $\mathrm{Ni}$ & $\mathrm{Mo}$ & $\mathrm{Mn}$ & $\mathrm{Si}$ & $\mathrm{C}$ & $\mathrm{P}$ & $\mathrm{S}$ & $\mathrm{N}$ & $\mathrm{Ti}$ & $\mathrm{Y}_{2} \mathrm{O}_{3}$ \\
\hline \hline bal. & 16.82 & 13.23 & 2.48 & 0.40 & 0.72 & 0.008 & 0.005 & 0.007 & 0.2 & 0.3 & 0.35 \\
\hline
\end{tabular}

\subsection{Atom Probe Tomography}

Specimens for APT were fabricated from small blanks $(0.25 \mathrm{~mm} \times 0.25 \mathrm{~mm} \times 10 \mathrm{~mm})$ that were cut from the bulk material. The blanks were electropolished into needle-shaped specimens with the use a standard loop method in a Simplex Electropointer and standard electrolytes[44]. The needle-shaped specimens were annular milled in a Dualbeam FEI Nova 200 Nanolab focused ion beam/scanning electron microscope (FIB/SEM) to ensure a circular cross section, as well as a suitable end radius and taper angle[45]. APT characterizations were performed in an energy-compensated CAMECA Instruments Inc. local electrode atom probe (LEAP ${ }^{\circledR}$ 4000X $\mathrm{HR}$ ). Due to the poor electrical and thermal conduction of these materials, the specimens were analyzed in laser-mode at a specimen temperature of $30 \mathrm{~K}$, a pulse repetition rate of $200 \mathrm{kHz}$, a focused laser beam energy of either 50 or $100 \mathrm{pJ}$, and a data collection rate between $0.5 \%$ and $4 \%$ ions per field evaporation pulse depending on the standing voltage applied to the specimen. The position of the laser beam on the apex of the specimen was adjusted automatically during the experiment to account for the field evaporation of material from the apex of the specimen and specimen drift. These conditions resulted in individual LEAP ${ }^{\circledR}$ datasets containing up to 600 million atoms. Surface regions that contained damage from the gallium ion beam were not used for analysis. Data analysis was performed with the use of CAMECA Instruments Inc. Integrated Visualization and Analysis Software (IVAS 3.6.6). The proxigrams[46] were calculated according to the isosurfaces defined by $6 \%$ decomposed oxygen concentration. The sizes of the oxygen-enriched nanoclusters are determined by the effective diameters $\left(d_{e f f}\right)$ based on the volumes $(V)$ defined by the oxygen isosurfaces, $d_{\text {eff }}=(6 V / \pi)^{1 / 3}[47]$. 


\subsection{WAXS and SAXS Investigations}

The in-situ tensile loading investigations were conducted at the 1-ID beamline at the Advanced Photon Source (APS), Argonne National Laboratory (ANL). The material was cut into miniature tensile specimens with the gauge sections of $1.20 \mathrm{~mm} \times 0.50 \mathrm{~mm} \times 5.00 \mathrm{~mm}$ by electrical discharge machining (EDM) so as to avert any dislocation propagation due to mechanical cutting. Uniaxial tensile load was applied to specimens until failure. The experiments were conducted at ambient temperature and at two elevated temperatures, $350^{\circ} \mathrm{C}$ and $550^{\circ} \mathrm{C}$. The displacement rate was controlled at $5 \times 10^{-4} \mathrm{~mm} \cdot \mathrm{s}^{-1}$ to get an approximate strain rate of $1 \times 10^{-4} \mathrm{~s}^{-1}$. The X-ray scattering was performed with a monochromatic $70 \mathrm{keV}$ beam with a $300 \mu \mathrm{m} \times 300 \mu \mathrm{m}$ cross-section. The "Hydra" detector array, which is composed of four GE RT41 detectors, was utilized to collect the WAXS signals, while the SAXS data were collected by a Scint-X detector with a beamstop to block the transmitted beam. Fig. 1 illustrates the in-situ experimental setup.

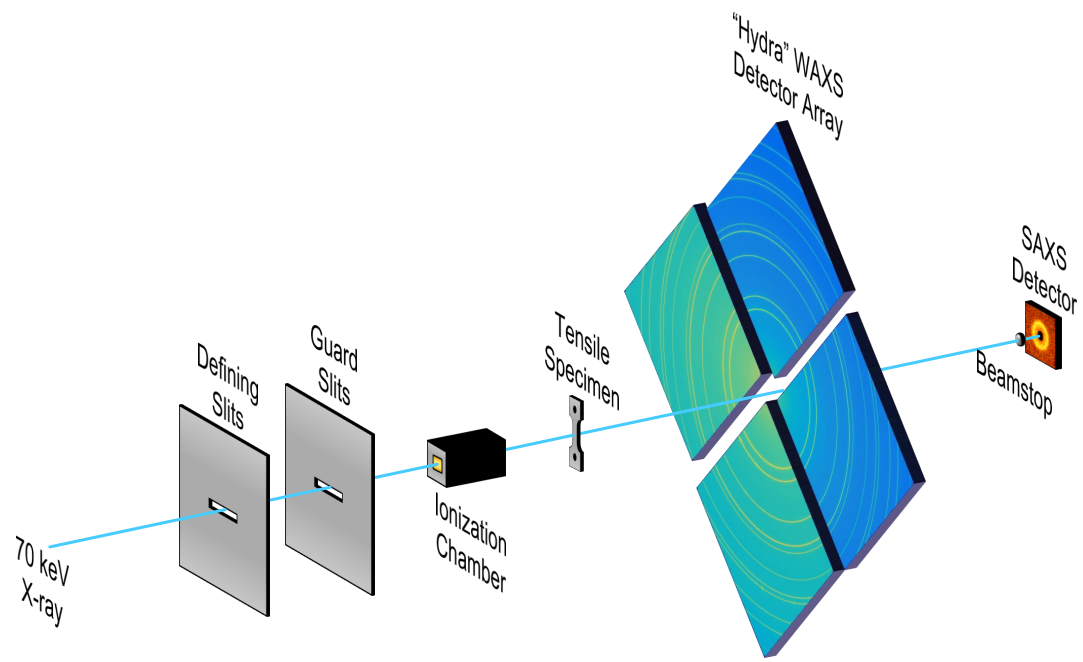

Figure 1: Synchrotron experiment setup.

The $10^{\circ}$ region of the Debye-Scherrer rings near the uniaxial tensile direction was integrated to give the lattice strain in that direction, $\varepsilon_{11}=\left(d-d_{0}\right) / d_{0}$. For the austenite matrix, the average bulk lattice strain was calculated from the lattice strains of $\{111\},\{200\},\{220\}$, and $\{311\}$ reflections using the weighted averaging algorithm developed by Daymond[48]:

$$
\bar{\varepsilon}=\frac{\sum_{h k l} \alpha_{h k l} \varepsilon_{h k l}}{\sum_{h k l} \alpha_{h k l}}
$$

where, $\bar{\varepsilon}$ is the average bulk lattice strain of the matrix, $\varepsilon_{h k l}$ is the lattice strain of the $\{h k l\}$ reflection, and $\alpha_{h k l}$ is the weight coefficient with the following definition:

$$
\alpha_{h k l}=T_{h k l} p_{h k l} E_{h k l} / \bar{E} .
$$

Here, $p_{h k l}$ is the multiplicity of the $\{h k l\}$ reflection, $E_{h k l}$ is the Young's modulus of the $\{h k l\}$ orientation, $\bar{E}$ is the average Young's modulus of the bulk austenite matrix, and $T_{h k l}$ is the Harris texture index[49]: 


$$
T_{h k l_{i}}=\frac{I_{h k l_{i}} / R_{h k l_{i}}}{\frac{1}{n} \sum_{j=1}^{n} I_{h k l_{j}} / R_{h k l_{j}}},
$$

where $I_{h k l}$ is the integrated intensity of the $\{h k l\}$ reflection and $R_{h k l}$ is the theoretical integrated intensity of the $\{h k l\}$ reflection produced by an untextured sample:

$$
R_{h k l}=\frac{1}{V^{2}}\left[|F|^{2} p\left(\frac{1+\cos ^{2} 2 \theta}{\sin ^{2} \theta \cos \theta}\right)\right] e^{-2 M},
$$

where $V$ is the volume of the unit cell, $F$ is the structure factor, $p$ is the multiplicity of the reflection, $\frac{1+\cos ^{2} 2 \theta}{\sin ^{2} \theta \cos \theta}$ is the Lorentz-polarization factor as a function of diffraction angle $\theta$, and $e^{-2 M}$ is the Debye-Waller temperature factor, which has the following form:

$$
e^{-2 M}=\exp \left[-\frac{B \sin ^{2} \theta}{\lambda^{2}}\right]
$$

and

$$
B=\frac{6 h^{2}}{m_{a} k \Theta}\left[\frac{\phi(x)}{x}+\frac{1}{4}\right]
$$

where $h$ is Plank constant, $m_{a}$ is the mass of atom, $k$ is Boltzmann constant, $\Theta$ is Debye temperature, and the reminder of Equation 6 is the Debye function. The integrated intensities can also be used to calculate the volume fractions of the corresponding phases[50]:

$$
V_{i}=\frac{\frac{1}{n_{i}} \sum_{j=1}^{n_{i}} \frac{I_{i}^{j}}{R_{i}^{j}}}{\frac{1}{n_{a}} \sum_{j=1}^{n_{a}} \frac{I_{a}^{j}}{R_{a}^{j}}+\frac{1}{n_{p_{1}}} \sum_{j=1}^{n_{p_{1}}} \frac{I_{p_{1}}^{j}}{R_{p_{1}}^{j}}+\frac{1}{n_{p_{2}}} \sum_{j=1}^{n_{p_{2}}} \frac{I_{p_{2}}^{j}}{R_{p_{2}}^{j}}+\ldots},
$$

where $V_{i}$ is the volume fraction of phase $i$; $i$ represents austenite (subscript ${ }_{a}$ ) and various precipitate phases (subscripts $p_{1}, p_{2} \ldots$ ); $I_{i}^{j}$ is the integrated intensity of the reflection of $j$ (for a specific $h k l$ ) for phase $i ; n_{i}$ is the number of the reflections analyzed for a certain phases; and $R_{i}^{j}$ is the material scattering factor for a specific phase $(i)$ and reflection $(j)$, which has the same expression as Equation 4.

Other information was obtained by analyzing the breadth of the WAXS peaks according to the modified W-H method. The modified W-H analysis usually gives the grain size and dislocation density of each phase. However, in the case of FCC alloys with low stacking fault energies (SFE), such as 304 and 316 steel, the evolution of stacking and twinning faults, which contributes significantly to the peak broadening, sometimes also plays a role in plastic deformation. Therefore, a modified W-H method that considers stacking and twinning faults was employed for the austenite phase[42]:

$$
\Delta K=\left(\frac{1.5 \alpha+\beta}{a}\right) W(g)+\frac{0.9}{D}+\left(\frac{\pi A^{2} b^{2}}{2}\right)^{\frac{1}{2}} \rho^{\frac{1}{2}}\left(K \bar{C}^{\frac{1}{2}}\right),
$$

where $\alpha$ is the stacking fault portion, $\beta$ is the twinning fault portion, $a$ is the lattice parameter, $W(g)$ is a reflection-dependent parameter given in Ref. [42], $D$ is the grain size, $A$ is an adjustable parameter that was chosen to be 1 for compatibility with a dislocation density of approximately $10^{14} \mathrm{~m}^{-2}, \bar{C}$ is the averaged contrast factor, which will be discussed in detail later, $K=2 \sin \theta / \lambda$, 
$\Delta K=2 \cos \theta \Delta \theta / \lambda, \theta$ is the diffraction angle, and $\Delta \theta$ is the breadth of the peak. A pseudo-Voigt function was used for peak fitting. The pseudo-Voigt peak has two components:

$$
p V(2 \theta)=I_{0}[\eta L(2 \theta)+(1-\eta) G(2 \theta)],
$$

where $I_{0}$ is the peak intensity, $L(2 \theta)$ is the Lorentzian component, $G(2 \theta)$ is the Gaussian component, and $\eta$ is the portion of the Lorentzian component. The breadth of the peak then has the following form:

$$
\Delta \theta=\omega\left[\pi \eta+(1-\eta)(\pi / \ln 2)^{1 / 2}\right],
$$

where $\omega$ is the half of the peak's FWHM. The values of $\bar{C}$ for edge $\left(\bar{C}_{e}\right)$ and screw $\left(\bar{C}_{s}\right)$ dislocations are different. This difference was utilized to quantify the fraction of the screw dislocations, $v_{s}$. To do this, two parameters that determine $\bar{C}$ were averaged separately according to the report of Ungár et al.[51]:

$$
\bar{C}=\bar{C}_{h 00}\left(1-q H^{2}\right),
$$

where $\bar{C}_{h 00}$ is the average contrast factor of $\{h 00\}$ reflections, $q$ is a material characteristic parameter, and $H^{2}=\left(h^{2} k^{2}+h^{2} l^{2}+k^{2} l^{2}\right) /\left(h^{2}+k^{2}+l^{2}\right)^{2}$ is a reflection parameter. Both $\bar{C}_{h 00}$ and $q$ are dependent on the elastic constants of the crystal[52] and can be calculated according to the method introduced by Ungár et al[51]. As both edge and screw dislocations exist in the crystal, the $\bar{C}$ has the following expression:

$$
\bar{C}=\left[v_{s} \bar{C}_{h 00, s}+\left(1-v_{s}\right) \bar{C}_{h 00, e}\right]\left\{1-\left[v_{s} q_{s}+\left(1-v_{s}\right) q_{e}\right] H^{2}\right\},
$$

where $v_{s}$ is the fraction of screw dislocations and subscripts $s_{s}$ and $e$ represent screw and edge dislocations, respectively. The $v_{s}$ term that maximizes the coefficient of determination $\left(R^{2}\right)$ when fitting Equation 8 was regarded as the optimized fraction of screw dislocations in the specimen. The specific parameters that were used to calculate the contrast factors are listed in Table 2.

Table 2: The parameters used in the calculation of the contrast factors
\begin{tabular}{cccc}
\hline Parameter & RT & $350^{\circ} \mathrm{C}$ & $550^{\circ} \mathrm{C}$ \\
\hline \hline$c_{11}[52]$ & 228 & 197 & 173 \\
$c_{12}[52]$ & 155 & 138 & 123 \\
$c_{44}[52]$ & 119 & 101 & 90 \\
$A=2 c_{44} /\left(c_{11}-c_{12}\right)$ & 3.260 & 3.424 & 3.600 \\
$c_{12} / c_{44}$ & 1.303 & 1.366 & 1.367 \\
$\bar{C}_{h 00, s}$ & 0.303 & 0.310 & 0.313 \\
$\bar{C}_{h 00, e}$ & 0.298 & 0.307 & 0.313 \\
$q_{s}$ & 2.395 & 2.418 & 2.440 \\
$q_{e}$ & 1.666 & 1.708 & 1.741 \\
\hline
\end{tabular}

Aside from WAXS analyses, SAXS is also capable of revealing some properties of the precipitates. From the SAXS data, the size distribution of the nanoparticles can be retrieved. In this study, the IRENA package[53] was utilized to perform the SAXS data analyses. The 
nanoparticles were assumed to be of unified sphere shape[54]. Namely, these nanoparticles have the form factor as follows:

$$
F^{2}=\exp \left\{-\frac{q^{2} R_{g}{ }^{2}}{3}\right\}+\frac{1.62}{R_{g}{ }^{4}}\left[\frac{\operatorname{erf}^{3}\left(q R_{g} / \sqrt{6}\right)}{q}\right]^{4},
$$

where $q=4 \pi \sin \theta / \lambda$ is the scattering vector and $R_{g}$ is the radius of gyration, which equals $\sqrt{3 / 5} r$ for spherical precipitates. The fitting of SAXS data was based on the maximum entropy algorithm[55, 56] so that the size distribution of nanoparticles could be assessed.

\subsection{Electron Microscopy Investigations}

The pre-strained ODS 316 specimens were mechanically thinned to $100 \mu \mathrm{m}$ and punched into $3 \mathrm{~mm}$ discs before being electropolished with 5\% perchloric acid and 95\% methanol at $-14^{\circ} \mathrm{C}$ using a Struer Tenupol-5 twin-jet polisher. The post-strained samples were lifted out from the gauge part of the tensile specimen by an FEI HELIOS 600i FIB. Diffraction contrast images were used to characterize the alterations in microstructure after straining, including the dislocation density evolution, after straining, whereas HRTEM was utilized to identify the orientation relationship of the fine nanoparticles. Physical selected area apertures are too large for the ultra-fine nanoparticles, so fast Fourier transformation (FFT) was adopted to produce the diffraction information of both the matrix and the oxide nanoparticles. In addition, STEM was employed to examine the chemical compositions of the nanoparticles larger than $5 \mathrm{~nm}$ with the aid of EDS. All the conventional TEM and HRTEM images were taken on a JEOL $2010 \mathrm{LaB}_{6}$ TEM, whereas the STEM-EDS data were collected on a JEOL 2010F EF-FEG TEM. In addition, a JEOL 7000F scanning electron microscope (SEM) was used to investigate the fracture surfaces of the post-strained specimens.

\section{Results and Discussion}

\subsection{Phase Identification of Precipitates}

Multiple phases are expected to precipitate in the ODS 316 stainless steel during the heat treatment that follows the mechanical alloying. These precipitates were first examined by the synchrotron WAXS technique. The $360^{\circ}$ integrated intensity vs. d-spacing is shown by Fig. 2 . Aside from the largest peaks that undoubtedly belong to the austenitic matrix of the ODS 316 steel, a variety of minor peaks are distinguishable. In fact, five different phases of precipitates were identified in this ODS 316 steel by synchrotron WAXS: TiN, hexagonal $\mathrm{YAlO}_{3}$ (yttrium aluminum hexagonal, $\mathrm{YAH}$ ), orthorhombic $\mathrm{YAlO}_{3}$ (yttrium aluminum perovskite, $\mathrm{YAP}$ ), pyrochlore $\mathrm{Y}_{2} \mathrm{Ti}_{2} \mathrm{O}_{7}$, and orthorhombic $\mathrm{Y}_{2} \mathrm{TiO}_{5}$. An unexpected element, aluminum, was found in the specimen, which might exist as impurity in the raw metal powder that was used in the mechanical alloying procedure. The volume fraction of each distinguishable precipitate phase was calculated based on Equation 7, and is listed in Table 3. These values were averaged from synchrotron WAXS data collected at seven different points on the gauge area of the miniature tensile specimen.

The STEM Z-contrast image in Fig. 3 shows the existence of two different types of precipitates. One has a polyhedral shape with a size usually larger than $100 \mathrm{~nm}$, whereas the other has a spherical shape with a size ranging from 20 to $80 \mathrm{~nm}$. EDS results show that the polyhedral precipitates are TiN, while the spherical ones are YAH and YAP. The Y-Ti-O nanoparticles, which have size smaller than $10 \mathrm{~nm}$, cannot be distinguished in Fig. 3. 


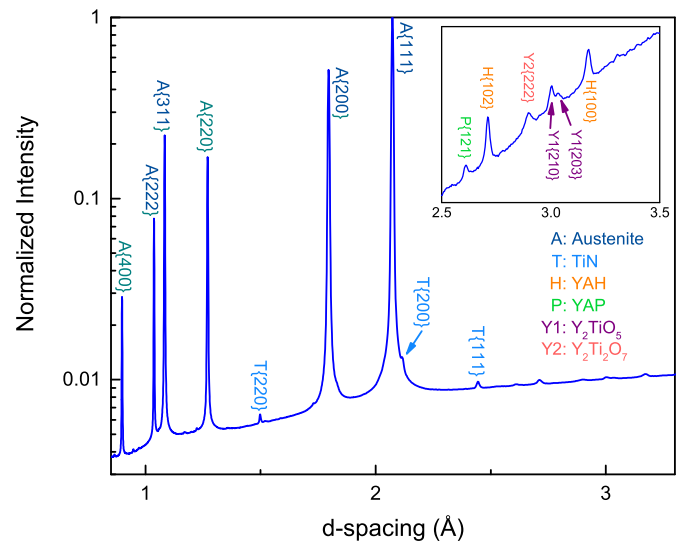

Figure 2: Phases identified using synchrotron $\mathrm{X}$-ray WAXS: aside from the austenite matrix, TiN, hexagonal- $\mathrm{YAlO}_{3}$ (YAH), orthorhombic- $\mathrm{YAlO}_{3}$ (YAP), $\mathrm{Y}_{2} \mathrm{Ti}_{2} \mathrm{O}_{7}$, and $\mathrm{Y}_{2} \mathrm{TiO}_{5}$ were distinguished. However, only the intensities of TiN, $\mathrm{YAH}$, and $\mathrm{Y}_{2} \mathrm{Ti}_{2} \mathrm{O}_{7}$ are sufficient for lattice strain analysis.

Table 3: Volume fractions of all the synchrotron-distinguishable precipitate phases in ODS 316 steel

\begin{tabular}{ccc}
\hline Formula & Structure & Volume Fraction \\
\hline \hline $\mathrm{TiN}$ & sodium chloride & $0.41 \pm 0.02 \%$ \\
$\mathrm{YAlO}_{3}$ & hexagonal & $0.40 \pm 0.03 \%$ \\
$\mathrm{YAlO}_{3}$ & perovskite & $0.29 \pm 0.11 \%$ \\
$\mathrm{Y}_{2} \mathrm{TiO}_{5}$ & orthorhombic & $0.10 \pm 0.02 \%$ \\
$\mathrm{Y}_{2} \mathrm{Ti}_{2} \mathrm{O}_{7}$ & pyrochlore & $0.05 \pm 0.01 \%$ \\
\hline
\end{tabular}




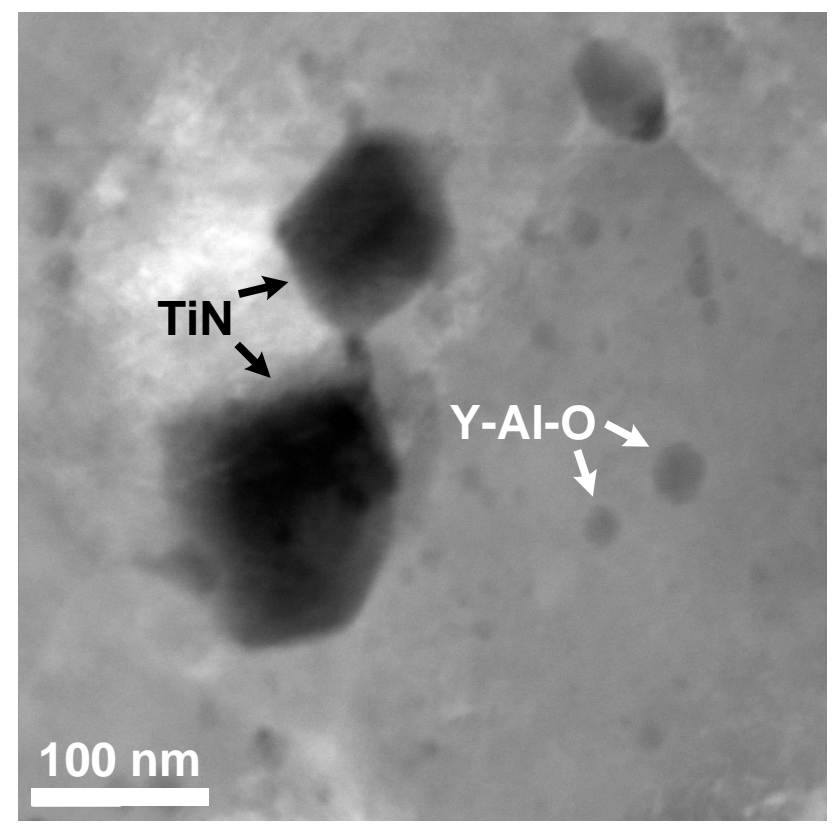

Figure 3: STEM Z-contrast image showing the TiN and Y-Al-O precipitates.

Synchrotron SAXS analysis was also employed to analyze the size distribution of the precipitates. A unified sphere model was used to fit the SAXS data, which yields the size distribution shown in Figs. 4 and 5. The polymodal size distribution implies that at least two groups of nanoparticles contribute to the SAXS signal, one with an average size around $7.5 \mathrm{~nm}$, and the other with a broader size distribution ranging from 20 to $70 \mathrm{~nm}$. Y-Al-O nanoparticles have size on the order of tens of nm, whereas Y-Ti-O nanoparticles have a finer particle size that is usually smaller than $10 \mathrm{~nm}$. The large Y-Al-O nanoparticles account for the YAH and YAP phases identified by synchrotron WAXS and STEM-EDS, while the fine Y-Ti-O nanoparticles are identified to be $\mathrm{Y}_{2} \mathrm{Ti}_{2} \mathrm{O}_{7}$ and $\mathrm{Y}_{2} \mathrm{TiO}_{5}$, as they still have adequate size to maintain stoichiometry. The ultra-fine Y-Ti-O nanoparticles (or nanoclusters, $<3 \mathrm{~nm}$ ), which can be examined by APT as shown in Fig. 6, do not have a well-defined stoichiometry or crystal structure, and therefore do not make contributions to WAXS signals. Therefore, the Y-Al-O to Y-Ti-O nanoparticle volume fraction ratio of 0.88 estimated by SAXS is much smaller than the ratio of 4.60 determined by WAXS, implying that approximately four-fifths of the Y-Ti-O phase has no well-defined crystalline structure. TiN precipitates, which usually exceed $100 \mathrm{~nm}$ in size, are too large for SAXS to capture. According to APT mass spectrum analysis, the Y-Ti-O nanoparticles still contain low, but non-negligible, $\mathrm{Al}$ content. However, the synchrotron WAXS results, along with the HREM results, which will be discussed shortly, indicate that the crystalline structures remain stable with the Al impurity. In the APT reconstruction shown in Fig. 6, there exists one nanoparticle-free zone and two nanoparticle-rich zones, indicating the heterogeneous distribution of the ultra-fine Y-Ti-O nanoparticles. In this case, the volume fraction of the Y-Ti-O nanoparticles of $0.08 \%$ determined by the APT data might not be representative due to the limited specimen volume. 


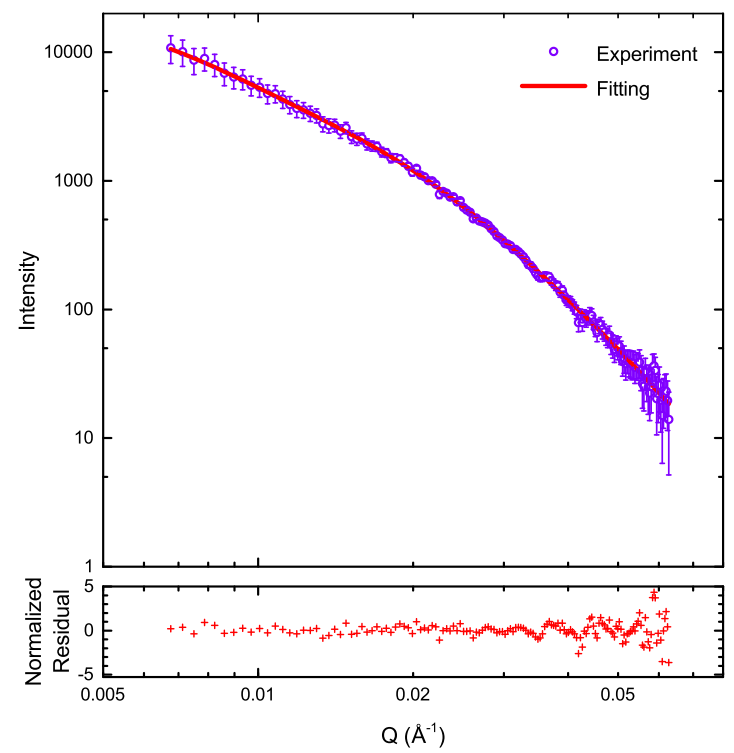

Figure 4: SAXS fitting.

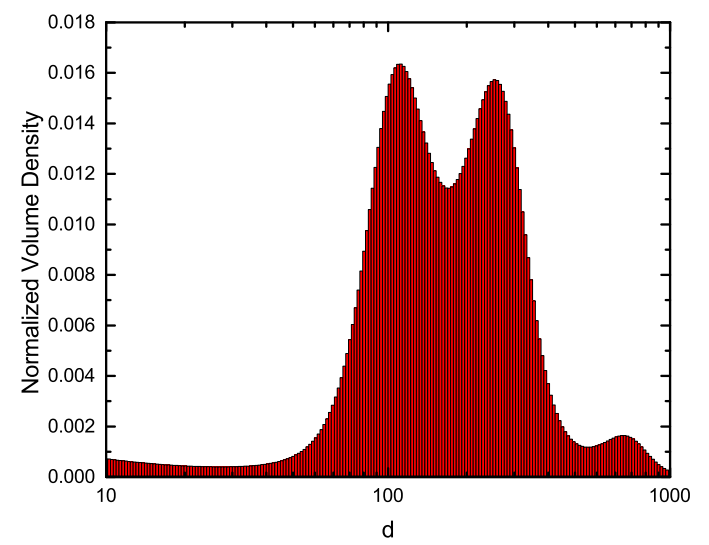

Figure 5: Size distribution of nanoparticles obtained by SAXS fitting. The prominent polymodal size distribution of the nanoparticles implies the existence of at least two groups of different precipitate phases. 


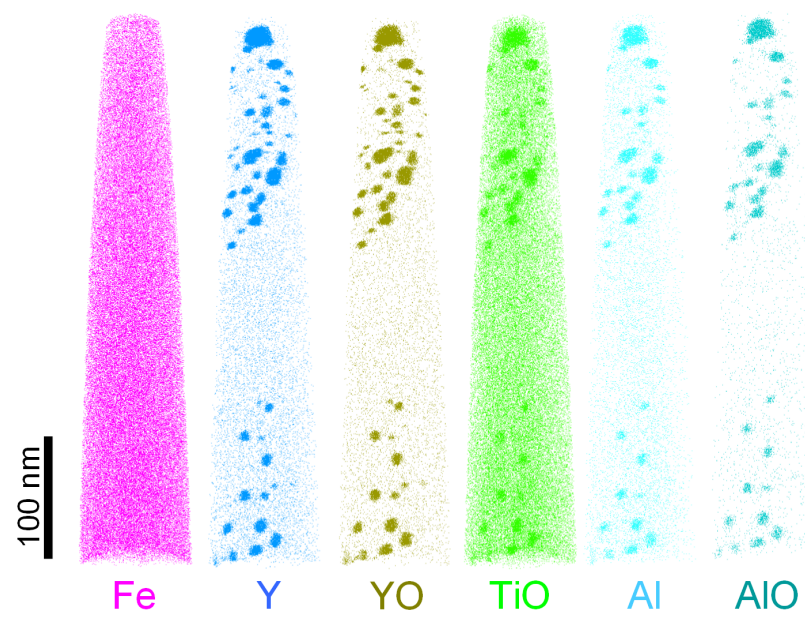

Figure 6: APT results of the ODS 316 steel. All the nanoparticles examined by APT are Y-Ti-O enriched nanoparticles with a non-negligible $\mathrm{Al}$ content. Even in this small specimen, there exist two particle-rich zones and one particle-free zone, showing the heterogeneous distribution of the ultra-fine oxide nanoparticles.

The existence of $\mathrm{Al}$, the known impurity in the raw metal powders, introduces the $\mathrm{Y}-\mathrm{Al}-\mathrm{O}$ nanoparticles. The precipitation mechanisms of Y-Al-O and Y-Ti-O nanoparticles differ. A recent first principle study[57] claims that the precipitation of the oxygen-enriched nanoparticles is initiated by the formation of $\mathrm{O}$-vacancy pairs, and that the relative magnitude of the oxygen-binding energies in the matrix $\left(E_{0}\right)$, interface $\left(E_{s}\right)$, and bulk $\left(E_{b}\right)$ determine whether the precipitation of oxygen-enriched nanoparticles is favored and how large the nanoparticles are likely to grow, given a specific oxygen concentration. This thermodynamic theory predicts that Y-Al-O nanoparticles always form prior to the $\mathrm{Y}-\mathrm{Ti}-\mathrm{O}$ nanoparticles as $\mathrm{Y}, \mathrm{Ti}$, and $\mathrm{Al}$ are all present with $\mathrm{O}$-vacancy pairs. More importantly, Y-Al-O nanoparticles are larger in size than the to Y-Ti-O nanoparticles. Therefore, with the existence of Al, the precipitation of Y-Ti-O is highly suppressed, as the Y-Al-O precipitate is thermodynamically preferred. As a result, few ultra-fine $(<10 \mathrm{~nm})$ nanoparticles can form with the presence of adequate $\mathrm{Al}[58]$. In the ODS 316 steel investigated in this study, the content of the impurity Al is limited, and hence Y-Al-O and Y-Ti-O nanoparticles coexist.

The orientation relationship of the nanoparticles not only determines the magnitude of the strain field due to the nanoparticles, but also influences their interactions with dislocations[59]. The orientation relationship is governed by the competition between the areal interface energy and volumetric strain energy. Therefore, large nanoparticles usually have random orientation relationship, whereas small nanoparticles tend to maintain a coherent or cubic-on-cubic orientation relationship with the matrix. Since $\mathrm{YAlO}_{3}$ precipitates (YAP and YAH) are relatively large, their orientation relationship is random. Two orientation relationships were observed for $\mathrm{Y}_{2} \mathrm{Ti}_{2} \mathrm{O}_{7}$, one of which is the $(002)_{\text {mat }}\left\|(\overline{4} 40)_{o x},[110]_{\text {mat }}\right\|[110]_{o x}$ coherent relationship shown in Fig. 7, while the other is the cubic-on-cubic relationship shown in Fig. 8. Both of these orientation relationships have been reported in another ODS 316 steel containing pyrochlore/fluorite Y-Ti-Hf-O precipitates[24], implying that they are common orientation relationships in austenitic ODS steels. However, another coherent relationship that was reported in the Hf-containing ODS 316, 
$(200)_{\text {mat }}\left\|(\overline{4} 40)_{o x},[001]_{\text {mat }}\right\|[110]_{o x}$, was not observed in this materials. The existence of these orientation relationships causes the interfaces between nanoparticles and the matrix to be strong sinks for point defects, enhancing the radiation tolerance of the ODS material. In addition, these orientation relationships allow the dislocations to cut through the nanoparticles when the nanoparticle is sufficiently small.
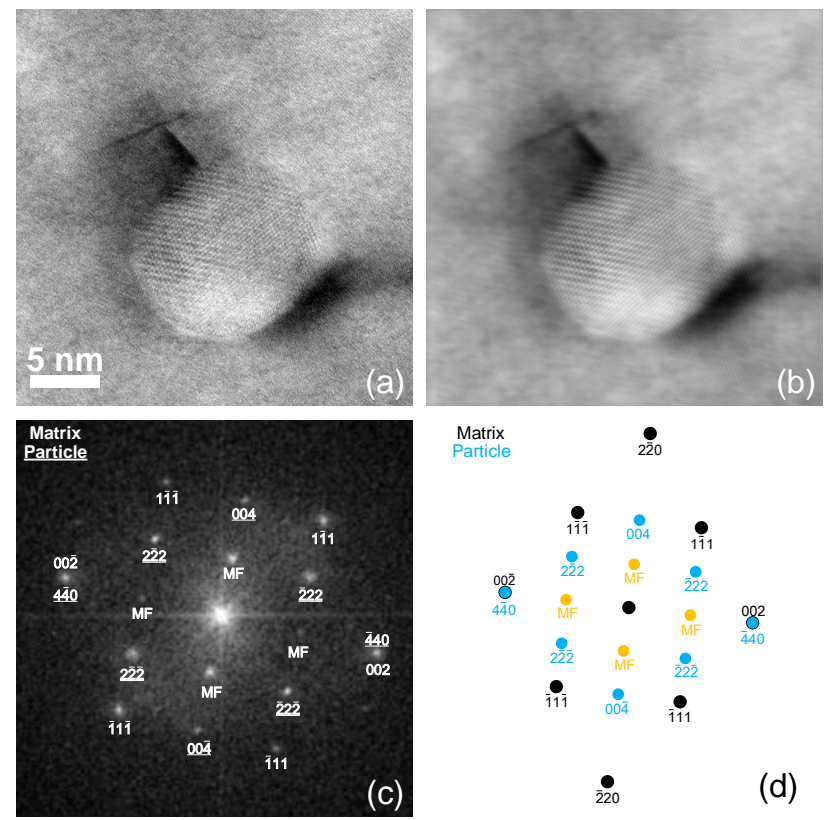

Figure 7: Coherent orientation relationship: $(002)_{\text {mat }}\left\|(\overline{4} 40)_{o x},[110]_{\text {mat }}\right\|[110]_{o x}$ : (a) an HRTEM image of a $\mathrm{Y}_{2} \mathrm{Ti}_{2} \mathrm{O}_{7}$ nanoparticle with coherent orientation relationship; (b) an FFT-IFFT enhanced contrast image of (a); (c) FFT of (a) showing the diffractions due to both the matrix and the particle; and (d) theoretically predicted FFT diffraction pattern. The spots labelled by "MF" correspond to the Moiré fringes formed due to the overlap of the matrix and the nanoparticle.

\subsection{Load Partitioning Phenomenon}

The in-situ tensile investigations were conducted on the ODS 316 miniature tensile specimens at room temperature (RT) and two elevated temperatures. The stress-strain curves of these three testing conditions are shown in Fig. 9. At RT, the yield strength (YS) and ultimate tensile strength (UTS) of the ODS 316 steel are $477 \mathrm{MPa}$ and $729 \mathrm{MPa}$, respectively. Both values are significantly higher than those of the ordinary 316 steel. The elongation is approximately $39 \%$ at RT. With an increase in temperature, the YS drops to $367 \mathrm{MPa}$ at $350^{\circ} \mathrm{C}$ and $328 \mathrm{MPa}$ at $550^{\circ} \mathrm{C}$. The ductility also decreases at elevated temperatures, but the fracture strain still exceeds $20 \%$. However, even at high temperatures, the ODS 316 steel still maintains adequate tensile strength and acceptable ductility compared with the 316L stainless steel at RT[60].

The lattice responses of various precipitate phases and the austenite matrix to the uniaxial tensile stress at RT are illustrated in Fig. 10(a). During elastic deformation, the lattice strains of all three distinguishable and analyzable precipitate phases are close to that of the austenite matrix, showing that the deformation of the precipitates is mainly due to the continuity condition 

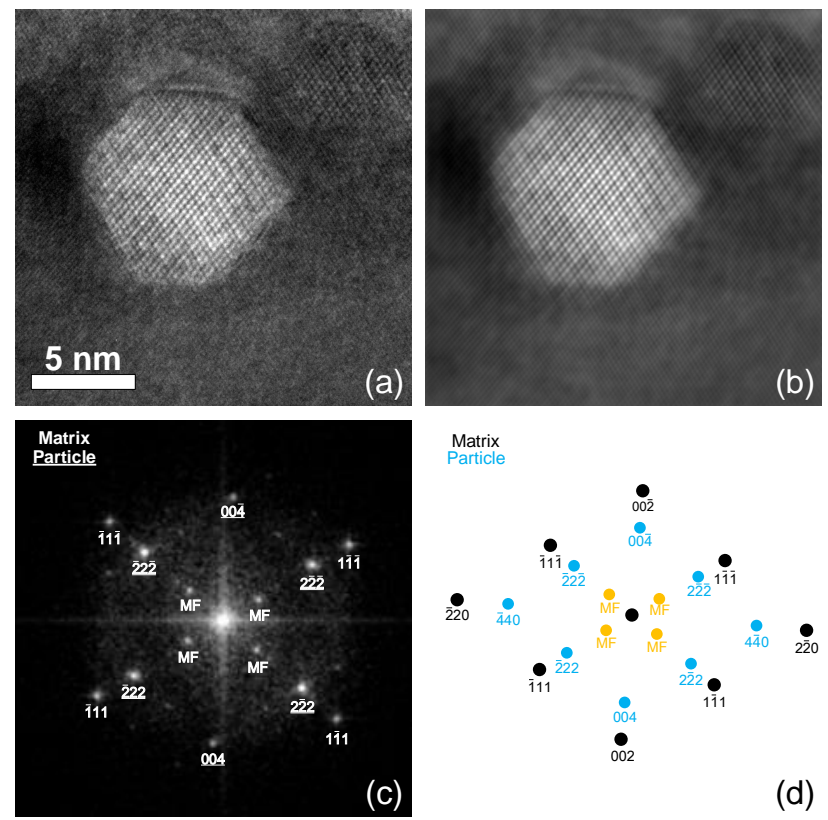

Figure 8: Cubic-on-cubic orientation relationship: (a) an HRTEM image of two $\mathrm{Y}_{2} \mathrm{Ti}_{2} \mathrm{O}_{7}$ nanoparticles with cubic-on-cubic relationship; (b) an FFT-IFFT enhanced contrast image of (a); (c) FFT of (a) showing the diffractions due to both matrix and the particle; and (d) FFT diffraction pattern from theoretical prediction. The spots labelled by "MF" correspond to the Moire fringes formed due to the overlap of the matrix and the nanoparticles.

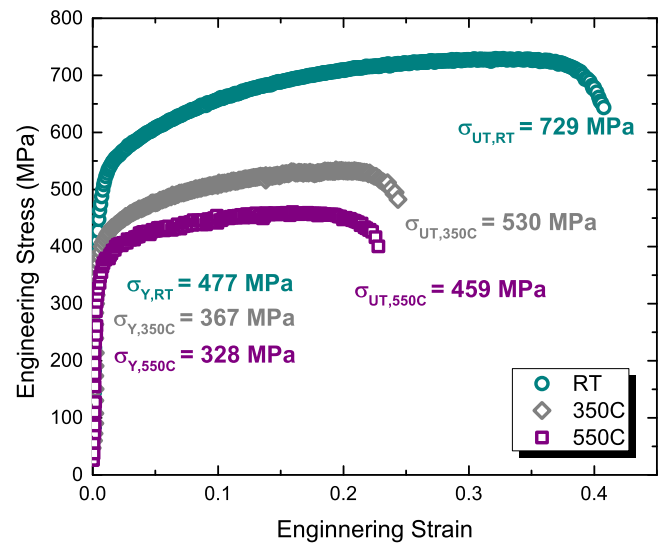

Figure 9: Strain-stress curve of the ODS 316 steel at three temperatures. 
at the interfaces. After the specimen yields, the lattice strain of the austenite matrix becomes much lower than that of the three precipitate phases. This difference in lattice strain implies that the particle-dislocation interactions transfer significant amounts of the stress to the precipitates. Therefore, the nanoparticles sustain higher loads than the austenite matrix. This load partitioning phenomenon, which originates from the particle-dislocation interaction mechanism, accounts for the outstanding tensile strength of the ODS 316 steel.
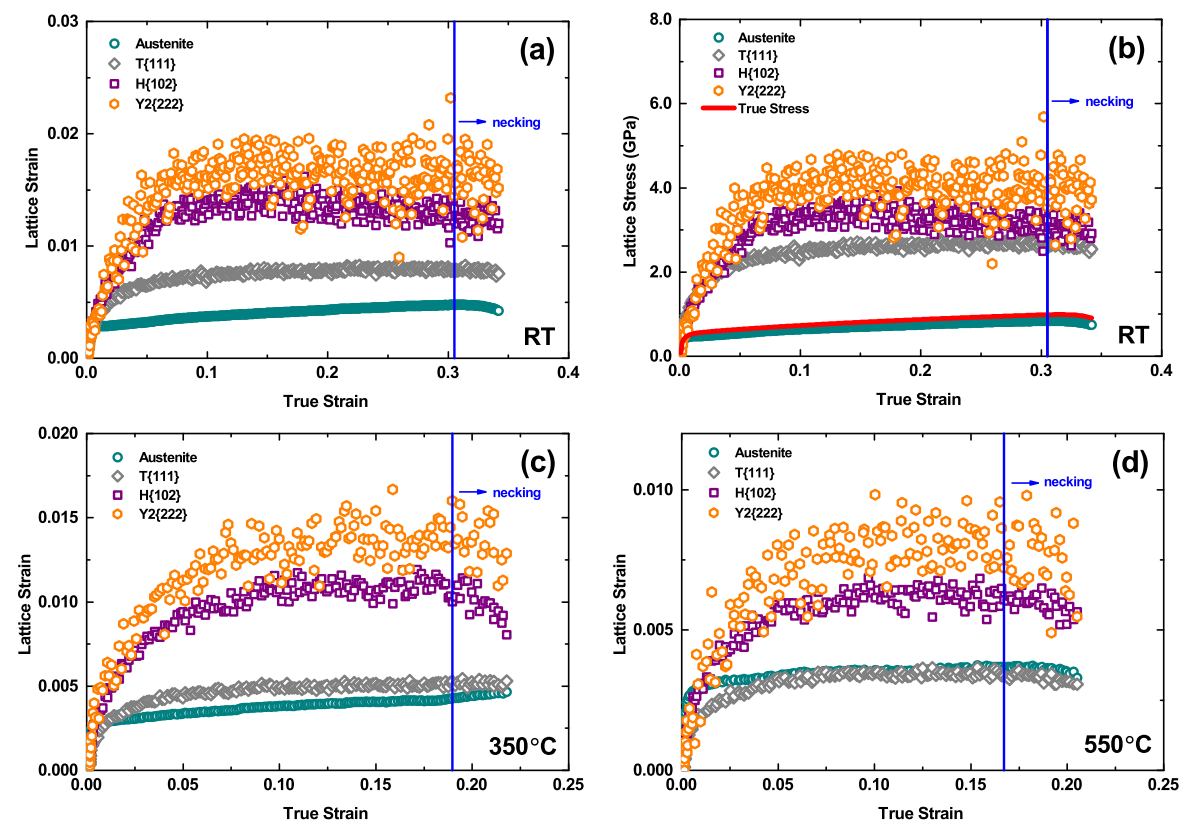

Figure 10: Lattice strain/stress evolution of different phases in ODS 316 steel: (a) lattice strain vs. true strain at RT; (b) lattice stress vs. true strain at RT; (c) lattice strain vs. true strain at $350^{\circ} \mathrm{C}$; (d) lattice strain vs true strain at $550^{\circ} \mathrm{C}$. The errors of the lattice strain values are approximately $\pm 3 \times 10^{-5}$ for austenite matrix, $\pm 9 \times 10^{-5}$ for TiN, $\pm 4 \times 10^{-4}$ for YAH and $\pm 1 \times 10^{-3}$ for $\mathrm{Y}_{2} \mathrm{Ti}_{2} \mathrm{O}_{7}$, respectively.

To better understand the load partitioning mechanism, especially its dependence on the precipitates, it is necessary to determine the actual stress of each precipitates phase and then compare the precipitate stress with the stress of the matrix. The stress value that is derived from the lattice strain of a certain phase is defined as the lattice stress of that phase. Because limited reflections of the precipitates phases are analyzable, only the lattice strains of the precipitates with specific orientations are available. Unfortunately, the three precipitates investigated in this study have anisotropic elasticity. Therefore, only the lattice stresses of these specifically-orientated precipitates were measured and taken to be representative of the phase. At RT, the elastic moduli of the precipitates were derived from the elastic stiffness tensors and were found to be: $E_{a}=193 \mathrm{GPa}[52]$, $E_{t}\{111\}=337 \mathrm{GPa}[61], E_{h}\{102\}=242 \mathrm{MPa}, E_{y_{2}}\{222\}=245 \mathrm{GPa}[62]$ (subscripts ${ }_{a}$ for austenite, ${ }_{t}$ for $\mathrm{TiN},{ }_{h}$ for $\mathrm{YAH}$, and $y_{2}$ for $\mathrm{Y}_{2} \mathrm{Ti}_{2} \mathrm{O}_{7}$ ). Here, the elastic constant of $\mathrm{YAH}$ was calculated 
using the first principle method due to a lack of existing references. With these Young's moduli, assuming uniaxial stresses, the lattice stresses of different precipitates and the austenite matrix can be calculated. The results are shown in Fig. 10(b).

The lattice stress data provides more useful information on the load partitioning phenomenon in ODS 316 steel than the elastic strain. First, as ceramics generally have higher stiffness than metallic phases, the difference in lattice stress between the austenite matrix and the precipitates is significant. Second, the load partitioning phenomenon has a strong dependence on particle size. The particle phase of the largest size, TiN, has the lowest lattice stress among the three analyzable precipitate phases. On the contrary, the finest precipitates, $\mathrm{Y}_{2} \mathrm{Ti}_{2} \mathrm{O}_{7}$ were found to sustain highest load. In previous observations in ferritic[7] and austenitic[24] ODS steels, where two types of precipitates with different sizes were found, a similar size effect was reported. In this case, three precipitates of different sizes exist, the results undoubtedly indicate that the finer the nanoparticles, the greater their contribution to the strengthening of the material.

At higher temperatures, characteristics of the load partitioning phenomenon change. The lattice responses of all distinguishable phases to the uniaxial tensile stress at $350^{\circ} \mathrm{C}$ and $550^{\circ} \mathrm{C}$ are respectively illustrated by Fig. 10(c) and (d). Due to the lack of reliable stiffness tensors for the precipitate phases at elevated temperatures, it is more appropriate to make comparisons using just lattice strain values rather than lattice stresses. At $350^{\circ} \mathrm{C}$, the difference in the lattice strain between TiN and the matrix is already marginal. When the temperature rises to $550^{\circ} \mathrm{C}$, the elastic deformation of TiN becomes nearly the same as that of austenite. Despite the fact that TiN still bears higher lattice stress than the matrix due to its larger Young's modulus, the interactions between dislocations and TiN particles are suppressed at elevated temperatures. On the other hand, oxide precipitate phases still remain, and have lattice strains much larger than that of the matrix at $550^{\circ} \mathrm{C}$. Therefore, the precipitate-strengthening mechanism due to the oxide nanoparticles accounts for, almost the entire enhancement of mechanical strength at elevated temperatures. This phenomenon implies the significance of fine oxide nanoparticles in pinning dislocations at high temperature, validating the rationale of developing ODS steels for high temperature applications, as only the ultra-fine oxide nanoparticles make significant contributions to pinning dislocations at elevated temperatures.

\subsection{The modified Williamson-Hall analyses on dislocation propagation}

Examination of the lattice responses reveals the temperature and size effects on the load partitioning phenomenon. Further fundamental investigations of these behaviors require information about the dislocation propagation in strained specimens. The modified W-H method is capable of not only assessing the dislocation density, but also distinguishing the edge and screw dislocations. At all three test temperatures, no stacking fault or twinning portions were observed by the modified W-H analysis. For higher temperature tests, the high value of SFE prevents the extensive formation of stacking faults and twinning faults. At RT, twinning deformations play an important role once the strain rate is high or the irradiation-induced defects preexist[60, 63]. However, when the strain rate is as low as $1 \times 10^{-4} \mathrm{~s}^{-1}$, dislocation glide accounts for the plasticity, even at RT. Meanwhile, the modified W-H analysis showed no prominent reduction in grain size. In this case, the relationship between the dislocation density $\rho$ and the true stress $\sigma_{T}$ can be described as follows:

$$
\sigma_{T}=\sigma_{0}+\alpha G b \rho^{1 / 2},
$$

where $\sigma_{0}$ is the stress needed for a dislocation to glide in the absence of other dislocations, $G$ is the shear modulus, $b$ is the length of the Burgers vector, $\alpha$ is a fitting constant. For all the three 
testing temperatures, Equation 14 was used to fit the dislocation density vs. true stress profiles shown in Fig. 11 (b), (d) and (f). The good linearity shown in this figure validates the dominance of dislocation glide in the plastic deformation of ODS 316 specimens tested in this study.

At RT, as shown in Fig. 11(a), edge dislocations dominate the plasticity of the ODS 316 steel. In the pre-strained sample, the intrinsic dislocations, which are predominately geometrically necessary dislocations (GNDs) due to the strain gradient formed during the manufacturing process, are screw-type. Both edge and screw dislocation densities increases in the beginning of plastic deformation. However, the screw dislocation density begins to decrease once the strain reaches about 0.1 and finally drops to nearly zero as the specimen is about to neck. Meanwhile, the edge dislocation density continues to increase until it reaches at its maximum at the necking point.

The situation changes, however, when the temperature is raised, as illustrated by Fig. 11(c). At $350^{\circ} \mathrm{C}$, both screw and edge dislocation densities continue to increase until failure. During this period, the screw dislocation density is always about twice the magnitude of the edge dislocation density. The faster dislocation density increase during the necking indicates that the synchrotron beam was hitting the necking area.

As shown in Fig. 11(e), when the temperature rises to $550^{\circ} \mathrm{C}$, the edge dislocation density reaches its maximum at approximately $3 \times 10^{13} \mathrm{~m}^{-2}$, and then remains constant, while the screw dislocation density continues to increase until it becomes nearly five times as the edge dislocation density at necking.

These strong temperature effects are interesting, and may play an important role in the nanoparticle-dislocation interaction, namely, the precipitate-strengthening mechanism. At elevated temperatures, the cross-slip $\left(Q_{C S}\right)$ and self diffusion $\left(Q_{S D}\right)$ energy barriers both become easier to overcome, resulting in the activation of two parallel mechanisms: the cross-slip of screw dislocations and the climb of edge dislocations. If the difference between $Q_{C S}$ and $Q_{S D}$ is sufficiently large, the mechanism with the lower barrier will be activated first with increase in temperature. In addition, the SFE increases at high temperatures[64], suppressing the dissociation of dislocations and then enhancing the cross-slip of screw dislocations. The rise of the screw dislocation portion implies the dominance of the cross-slip. Therefore, in this ODS 316 steel, $Q_{C S}$ is much lower than $Q_{S D}$ so that the cross-slip is activated at $550^{\circ} \mathrm{C}$, while the climb is still somewhat negligible. This also explains the degradation in the strengthening due to TiN. Because TiN precipitates are large and sparse, screw dislocations can bypass them easily by cross-slip. For finer and denser oxide nanoparticles, simple cross-slip cannot prevent the dislocation from being pinned by other nanoparticles. Instead, the Hirsch mechanism, a particle-dislocation interaction mechanism involving cross-slips, requires a similar magnitude of critical resolved shear stress $[65,66,67,68]$ and therefore does not reduce the strengthening effect. As a result, finer and denser oxide particles strengthen the material up to at least $550^{\circ} \mathrm{C}$.

\subsection{Electron microscopy investigations of post-strained specimens}

TEM was used to examine the foils lifted out from the tensile specimens after failure using FIB. The regions of interest were selected in gauge areas but away from the necking regions. Therefore, these specimens represents conditions near the onset of necking, namely, around the UTS. At all tested temperatures, multiple subgrains formed inside the original grains. More importantly, the dislocation densities were measured according to the bright field TEM images, as shown in Fig. 12. The values are consistent with those obtained from the modified W-H method, validating the reliability of both methods.

The fracture surface of the strained specimens were examined by SEM. For all temperatures, nanoparticles within dimples were the major features on the fracture surfaces, as shown in Fig. 

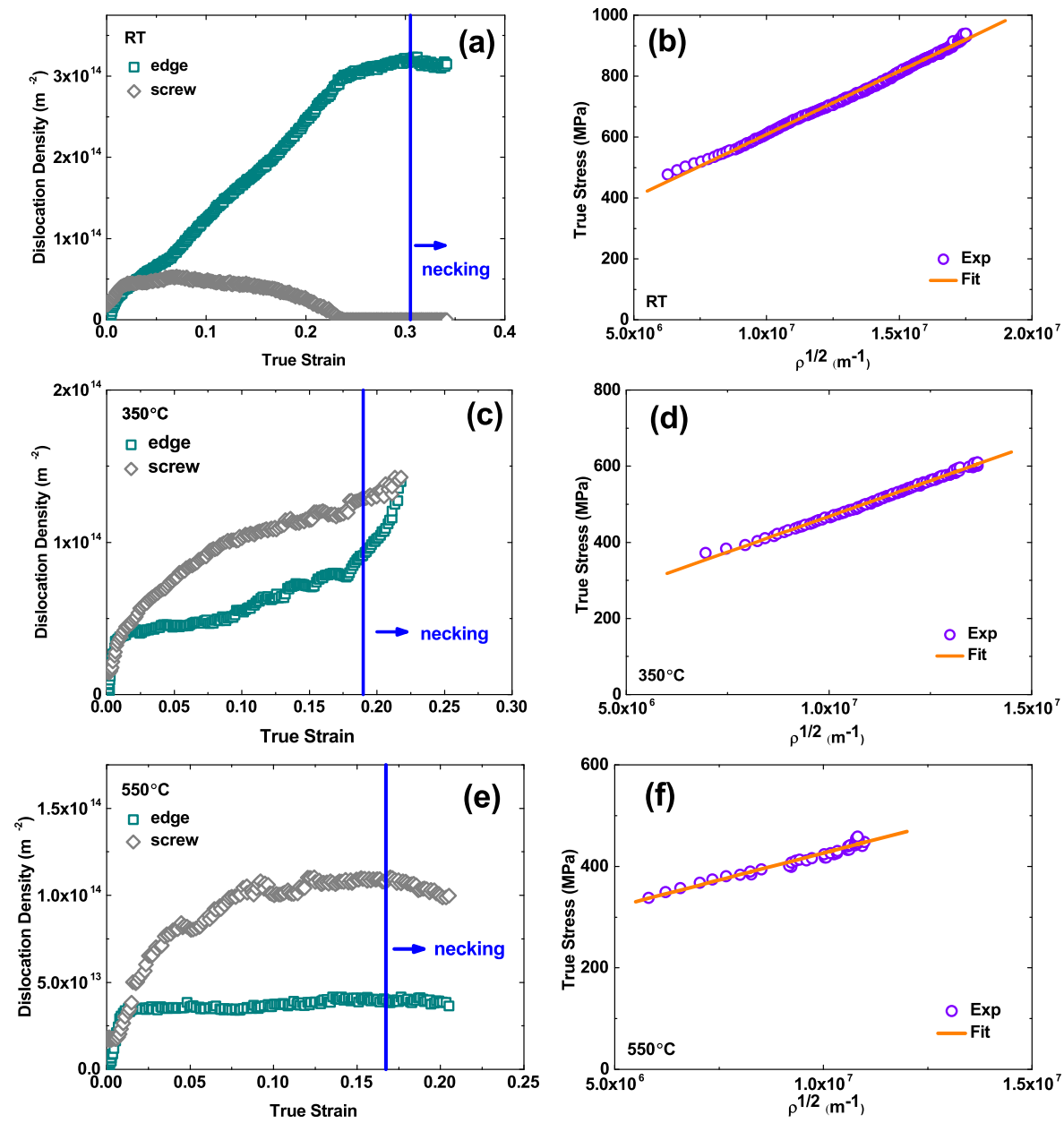

Figure 11: Dislocation density evolution in the matrix: (a) dislocation propagation at RT; (b) dislocation evolution compared with true stress at RT; (c) dislocation propagation at $350^{\circ} \mathrm{C}$; (d) dislocation evolution compared with true stress at $350^{\circ} \mathrm{C}$; (e) dislocation propagation at $550^{\circ} \mathrm{C}$; (f) dislocation evolution compared with true stress at $550^{\circ} \mathrm{C}$. 

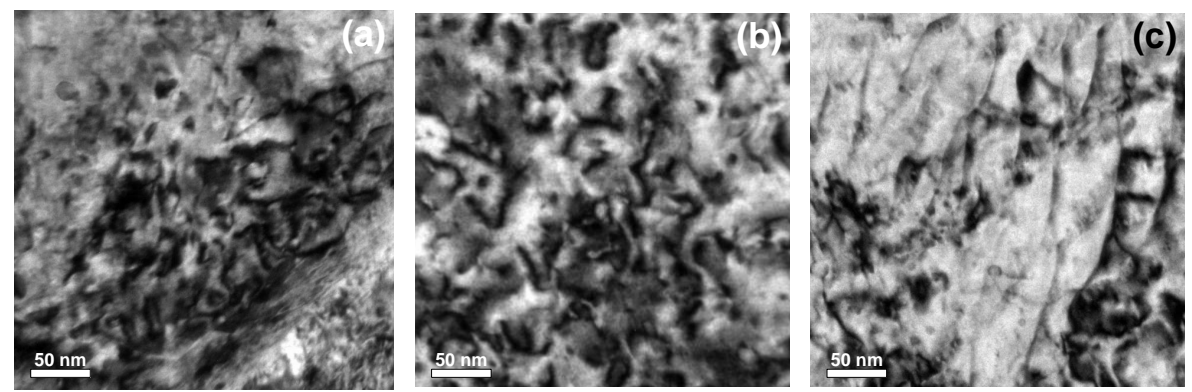

Figure 12: TEM bight field images of the gauge areas of the post strained specimens showing different dislocation densities: (a)RT, $3.8 \times 10^{14} \mathrm{~m}^{-2}$; (b) $350^{\circ} \mathrm{C}, 2.2 \times 10^{14} \mathrm{~m}^{-2}$; and (c) $550^{\circ} \mathrm{C}, 1.7 \times 10^{14} \mathrm{~m}^{-2}$. These TEM measured dislocation densities are comparable with those estimated by the modified W-H analyses: $3.15 \times 10^{14} \mathrm{~m}^{-2}$ (RT), $1.98 \times 10^{14} \mathrm{~m}^{-2}\left(350^{\circ} \mathrm{C}\right)$, and $1.49 \times 10^{14} \mathrm{~m}^{-2}\left(550^{\circ} \mathrm{C}\right)$.
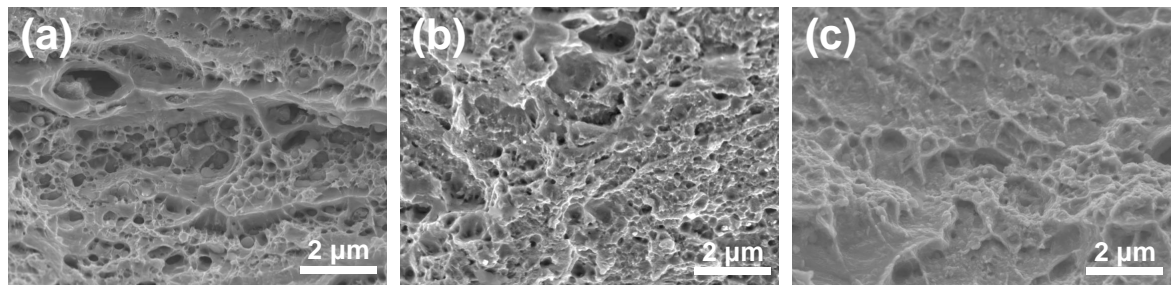

Figure 13: SEM images of fracture surfaces of the specimens strained at different temperatures: (a) RT; (b) $350^{\circ} \mathrm{C}$; and (c) $550^{\circ} \mathrm{C}$ 
13. Cracks were initiated by the voids formed on the nanoparticle interfaces. As temperature increases, the cleavage portion of that fracture surface increases, explaining the decrease in elongation. The features on the fracture surface of the $550^{\circ} \mathrm{C}$-strained specimen look blurry, which is mainly due to oxidation at high temperatures.

\section{Conclusion}

In this study, a systematic combination of advanced characterization techniques were adopted to investigate the precipitate-strengthening behaviors and the fundamental microstructural mechanisms behind these behaviors in an ODS 316 steel. Five different precipitate phases, TiN, YAH, YAP, $\mathrm{Y}_{2} \mathrm{TiO}_{5}$, and $\mathrm{Y}_{2} \mathrm{Ti}_{2} \mathrm{O}_{7}$, were identified by synchrotron WAXS and confirmed by STEM-EDS and APT analyses. Synchrotron SAXS fitting yielded the size distribution of the oxide nanoparticles, which is consistent with the STEM observation. Small $\mathrm{Y}_{2} \mathrm{Ti}_{2} \mathrm{O}_{7}$ nanoparticles $(<4 \mathrm{~nm})$ were found to have coherent or cubic-on-cubic orientation relationships with the austenite matrix. Three precipitate phases, TiN, YAH and $\mathrm{Y}_{2} \mathrm{Ti}_{2} \mathrm{O}_{7}$, which happen to have different size distributions, were analyzed using in-situ synchrotron tensile tests. The following conclusions can then be drawn based on the lattice strain evolution and the diffraction peak broadening at room and elevated temperatures:

1. Among the three types of analyzable precipitates, the finest $\mathrm{Y}_{2} \mathrm{Ti}_{2} \mathrm{O}_{7}$ nanoparticles sustain the highest load, whereas the coarsest TiN particles bear the lowest load. The particle size effect on the load partitioning phenomenon is significant, and the smaller the size, the great the stress that can be sustained.

2. As the temperature rises, the lattice strain of TiN falls to the same level of the matrix. However, the lattice strains of the oxide phases remain much higher than those of the matrix. The dense and dispersed distribution of oxide precipitates is the key to maintaining excellent mechanical strength at elevated temperatures.

3. The dislocation density decreases with increasing temperature. In addition, edge dislocations play the dominant role in the plasticity at RT, whereas screw dislocations account for the high temperature plastic deformation. The cross-slip of screw dislocation is activated at $550^{\circ} \mathrm{C}$, whereas the climb of edge dislocations requires even higher temperatures.

\section{Acknowledgement}

This work was supported by 973 DOE INL 120293. The TEM experiments were carried out in part at the Frederick Seitz Materials Research Laboratory Central Facilities, University of Illinois, which is partially supported by the U.S. Department of Energy (DOE) under grants DEFG02-07ER46453 and DE-FG02-07ER46471.Atom probe tomography (APT) was conducted at the Center for Nanophase Materials Sciences, which is a DOE Office of Science User Facility. M.K.M. was sponsored by the Materials Sciences and Engineering Division, Office of Basic Energy Sciences, U.S. DOE. This research used sources of the Advanced Photon Source, a U.S. DOE Office of Science User Facility operated for the DOE Office of Science by Argonne National Laboratory under Contract No. DE-AC02-06CH11357. 


\section{References}

[1] S. J. Zinkle, G. Was, Acta Mater. 61 (2013) 735-758.

[2] G. S. Was, P. L. Andresen, J. Mater. 44 (1992) 8-13.

[3] E. West, G. Was, J. Nucl. Mater. 392 (2009) 264-271.

[4] M. Del Giacco, A. Weisenburger, A. Jianu, F. Lang, G. Mueller, J. Nucl. Mater. 421 (2012) 39-46.

[5] K. Murty, I. Charit, J. Nucl. Mater. 383 (2008) 189-195.

[6] S. Ukai, S. Mizuta, M. Fujiwara, T. Okuda, T. Kobayashi, J. Nucl. Sci. Technol. 39 (2002) 778-788.

[7] K. Mo, Z. Zhou, Y. Miao, D. Yun, H.-M. Tung, G. Zhang, W. Chen, J. Almer, J. F. Stubbins, J. Nucl. Mater. 455 (2014) 376-381.

[8] A. Kimura, R. Kasada, N. Iwata, H. Kishimoto, C. Zhang, J. Isselin, P. Dou, J. Lee, N. Muthukumar, T. Okuda, et al., J. Nucl. Mater. 417 (2011) 176-179.

[9] M. Bachhav, G. Robert Odette, E. A. Marquis, Scr. Mater. 74 (2014) 48-51.

[10] W.-Y. Chen, Y. Miao, Y. Wu, C. A. Tomchik, K. Mo, J. Gan, M. A. Okuniewski, S. A. Maloy, J. F. Stubbins, J. Nucl. Mater. 462 (2015) 242-249.

[11] F. Garner, M. Toloczko, B. Sencer, J. Nucl. Mater. 276 (2000) 123-142.

[12] M. Miller, D. Hoelzer, E. Kenik, K. Russell, Intermetallics 13 (2005) 387-392.

[13] G. Odette, M. Alinger, B. Wirth, Annu. Rev. Mater. Res. 38 (2008) 471-503.

[14] L. L. Hsiung, M. J. Fluss, S. J. Tumey, B. W. Choi, Y. Serruys, F. Willaime, A. Kimura, Phys. Rev. B 82 (2010) 184103.

[15] A. Steckmeyer, M. Praud, B. Fournier, J. Malaplate, J. Garnier, J. Béchade, I. Tournié, A. Tancray, A. Bougault, P. Bonnaillie, J. Nucl. Mater. 405 (2010) 95-100.

[16] K. Yutani, H. Kishimoto, R. Kasada, A. Kimura, J. Nucl. Mater. 367 (2007) 423-427.

[17] J. Chen, P. Jung, W. Hoffelner, H. Ullmaier, Acta Mater. 56 (2008) 250-258.

[18] Q. Li, C. Parish, K. Powers, M. Miller, J. Nucl. Mater. 445 (2014) 165-174.

[19] P. Edmondson, C. Parish, Q. Li, M. Miller, J. Nucl. Mater. 445 (2014) 84-90

[20] M. Wang, Z. Zhou, H. Sun, H. Hu, S. Li, Mater. Sci. Eng. A 559 (2013) 287-292.

[21] H. Oka, Y. Yamazaki, H. Kinoshita, N. Hashimoto, S. Ohnuki, S. Yamashita, S. Ohtsuka, in: MRS Proceedings, volume 1298, Cambridge Univ Press, pp. mrsf10-1298.

[22] H. Oka, M. Watanabe, H. Kinoshita, T. Shibayama, N. Hashimoto, S. Ohnuki, S. Yamashita, S. Ohtsuka, J. Nucl Mater. 417 (2011) 279-282.

[23] H. Oka, M. Watanabe, N. Hashimoto, S. Ohnuki, S. Yamashita, S. Ohtsuka, J. Nucl. Mater. (2013).

[24] Y. Miao, K. Mo, B. Cui, W.-Y. Chen, M. Miller, K. Powers, M. V., G. D., J. Almer, I. Robertson, J. F. Stubbins, Mater. Charact. 101 (2015) 136-143.

[25] Y. Miao, K. Mo, Z. Zhou, X. Liu, K.-C. Lan, G. Zhang, M. K. Miller, K. A. Powers, J. Almer, J. F. Stubbins, Mater. Sci. Eng. A 625 (2015) 146-152.

[26] M. Klimiankou, R. Lindau, A. Möslang, Micron. 36 (2005) 1-8.

[27] M. C. Brandes, L. Kovarik, M. K. Miller, M. J. Mills, J. Mater. Sci. 47 (2012) 3913-3923.

[28] A. Certain, K. G. Field, T. R. Allen, M. Miller, J. Bentley, J. Busby, J. Nucl. Mater. 407 (2010) 2-9.

[29] M. K. Miller, C. M. Parish, Mater. Sci. Technol. 27 (2011) 729-734.

[30] V. J. Araullo-Peters, B. Gault, S. L. Shrestha, L. Yao, M. P. Moody, S. P. Ringer, J. M. Cairney, Scr. Mater. 66 (2012) 907-910.

[31] A. Hirata, T. Fujita, Y. Wen, J. Schneibel, C. Liu, M. Chen, Nat. Mater. 10 (2011) 922-926.

[32] M. Klimiankou, R. Lindau, A. Möslang, J. Cryst. Growth. 249 (2003) 381-387.

[33] L. Hsiung, M. Fluss, S. Tumey, J. Kuntz, B. El-Dasher, M. Wall, B. Choi, A. Kimura, F. Willaime, Y. Serruys, J. Nucl. Mater. 409 (2011) 72-79.

[34] J. Ribis, Y. De Carlan, Acta. Mater. 60 (2012) 238-252.

[35] J. S. Pedersen, Phys. Rev. B 47 (1993) 657.

[36] X. Pan, X. Wu, K. Mo, X. Chen, J. Almer, J. Ilavsky, D. R. Haeffner, J. F. Stubbins, J. Nucl. Mater. 407 (2010) $10-15$.

[37] X. Pan, X. Wu, X. Chen, K. Mo, J. Almer, D. R. Haeffner, J. F. Stubbins, J. Nucl. Mater. 398 (2010) 220-226.

[38] M. Li, L. Wang, J. D. Almer, Acta Mater. 76 (2014) 381 - 393.

[39] L. Wang, M. Li, J. Almer, Acta Mater. 62 (2014) 239-249.

[40] K. Mo, H.-M. Tung, J. Almer, M. Li, X. Chen, W. Chen, J. B. Hansen, J. F. Stubbins, J. Press. Vess. Technol. 135 (2013) 021502.

[41] G. Zhang, K. Mo, Y. Miao, X. Liu, J. Almer, Z. Zhou, J. F. Stubbins, Mater. Sci. Eng. A (2015) doi:doi:10.1016/j.msea.2015.04.037.

[42] T. Ungár, in: Materials Science Forum, volume 278, Trans Tech Publ, pp. 151-157.

[43] M. Wang, Z. Zhou, Z. Yan, P. Yu, H. Sun, Acta. Metall. Sinica. 49 (2013) 153-158. 
[44] M. K. Miller, Atom probe tomography: Analysis at the atomic level, Springer, New York, NY, 2000.

[45] M. K. Miller, K. F. Russell, K. Thompson, R. Alvis, D. J. Larson, Microsc. Microanal. 13 (2007) $428-436$.

[46] O. C. Hellman, J. A. Vandenbroucke, J. Rüsing, D. Isheim, D. N. Seidman, Microsc. Microanal. 6 (2000) $437-444$

[47] M. Miller, C. Parish, H. Bei, J. Nucl. Mater. (2014).

[48] M. R. Daymond, J. Appl. Phys. 96 (2004) 4263-4272.

[49] V. Valvoda, M. Järvinen, Powder Diffr. 5 (1990) 200-203.

[50] A. K. De, D. C. Murdock, M. C. Mataya, J. G. Speer, D. K. Matlock, Scr. Mater. 50 (2004) 1445-1449.

[51] T. Ungár, I. Dragomir, Á. Révész, A. Borbély, J. Appl. Crystallogr. 32 (1999) 992-1002.

[52] M. Daymond, P. Bouchard, Metall. Mater. Trans. A 37 (2006) 1863-1873.

[53] J. Ilavsky, P. R. Jemian, J. Appl. Crystallogr. 42 (2009) 347-353.

[54] G. Beaucage, J. Appl. Crystallogr. 28 (1995) 717-728.

[55] J. Potton, G. Daniell, B. Rainford, J. Appl. Crystallogr. 21 (1988) 663-668.

[56] P. Jemian, G. Long, F. Lofaj, S. Wiederhorn, in: MRS Proceedings, volume 590, Cambridge Univ Press, p. 131.

[57] H. Zhao, C. L. Fu, M. Krcmar, M. K. Miller, Phys. Rev. B 84 (2011) 144115.

[58] P. Dou, A. Kimura, T. Okuda, M. Inoue, S. Ukai, S. Ohnuki, T. Fujisawa, F. Abe, Acta Mater. 59 (2011) $992-1002$.

[59] S. Campos, H. J. Kestenbach, E. Morales, Metall. Mater. Trans. A 32 (2001) 1245-1248.

[60] X. Wu, X. Pan, J. C. Mabon, M. Li, J. F. Stubbins, J. Nucl. Mater. 356 (2006) 70-77.

[61] M. Zhang, J. He, Surf. Coat. Technol. 142 (2001) 125-131.

[62] Y. Luan, Elastic properties of complex transition metal oxides studied by Resonant Ultrasound Spectroscopy, Ph.D thesis, University of Tennessee, Knoxville, 2011.

[63] E. Lee, M. Yoo, T. Byun, J. Hunn, K. Farrell, L. Mansur, Acta Mater. 49 (2001) 3277-3287.

[64] T. Byun, Acta Mater. 51 (2003) 3063-3071.

[65] M. Ashby, On the Orowan Stess, MIT Press, 1969.

[66] F. Humphreys, P. Hirsch, P. Roy. Soc. Lond. A Mat. (1970) 73-92.

[67] F. Humphreys, S. AT, Surf. Sci. 31 (1972) 389-421.

[68] F. Humphreys, Dislocation-particle interactions, Dislocations and properties of real materials, Inst. Metals, London,, 1984. 

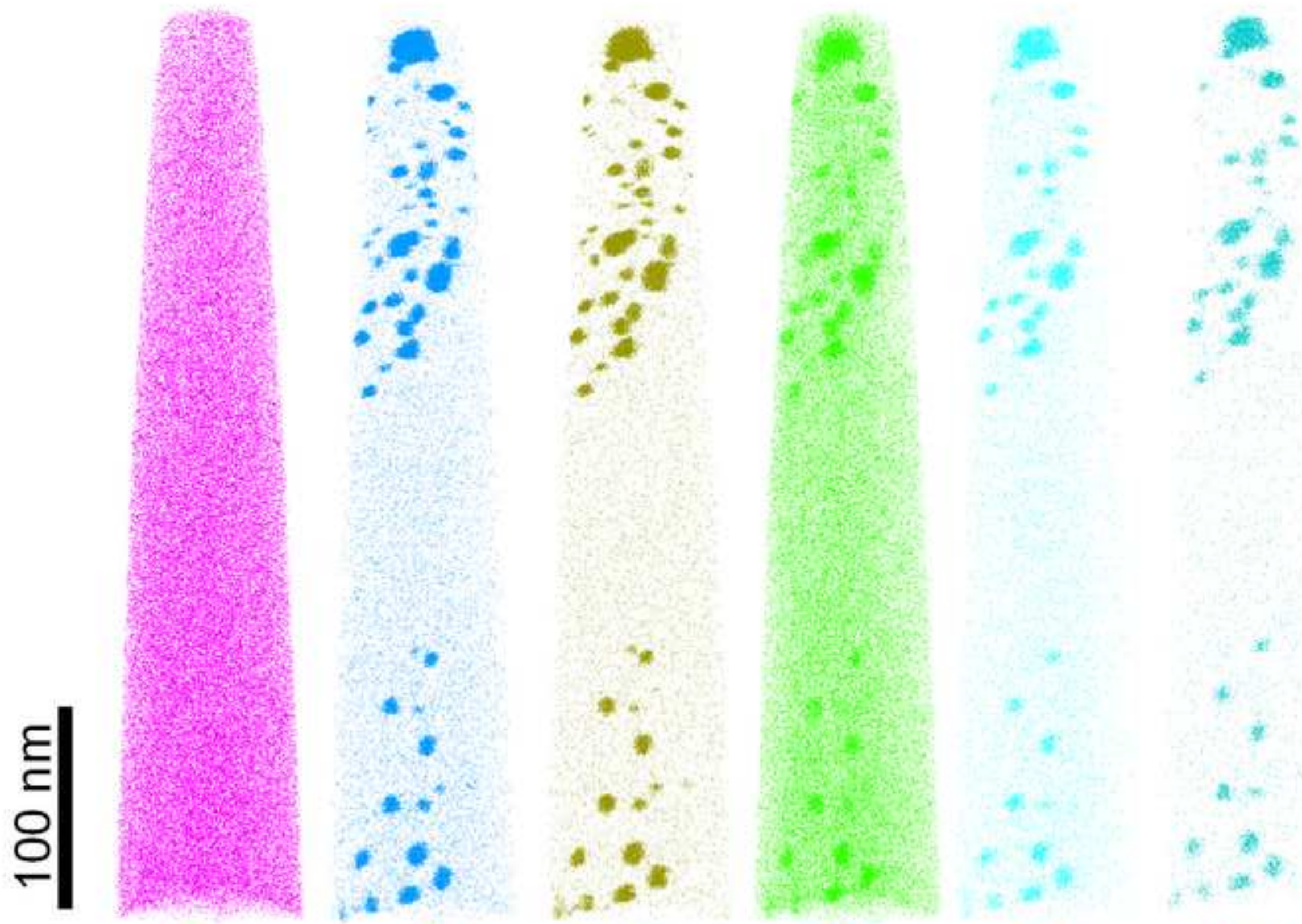

$\mathrm{Fe}$

YO

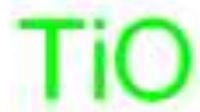

Al

AlO 


\section{$5 \mathrm{~nm}$}

\section{Matrix \\ Particle}

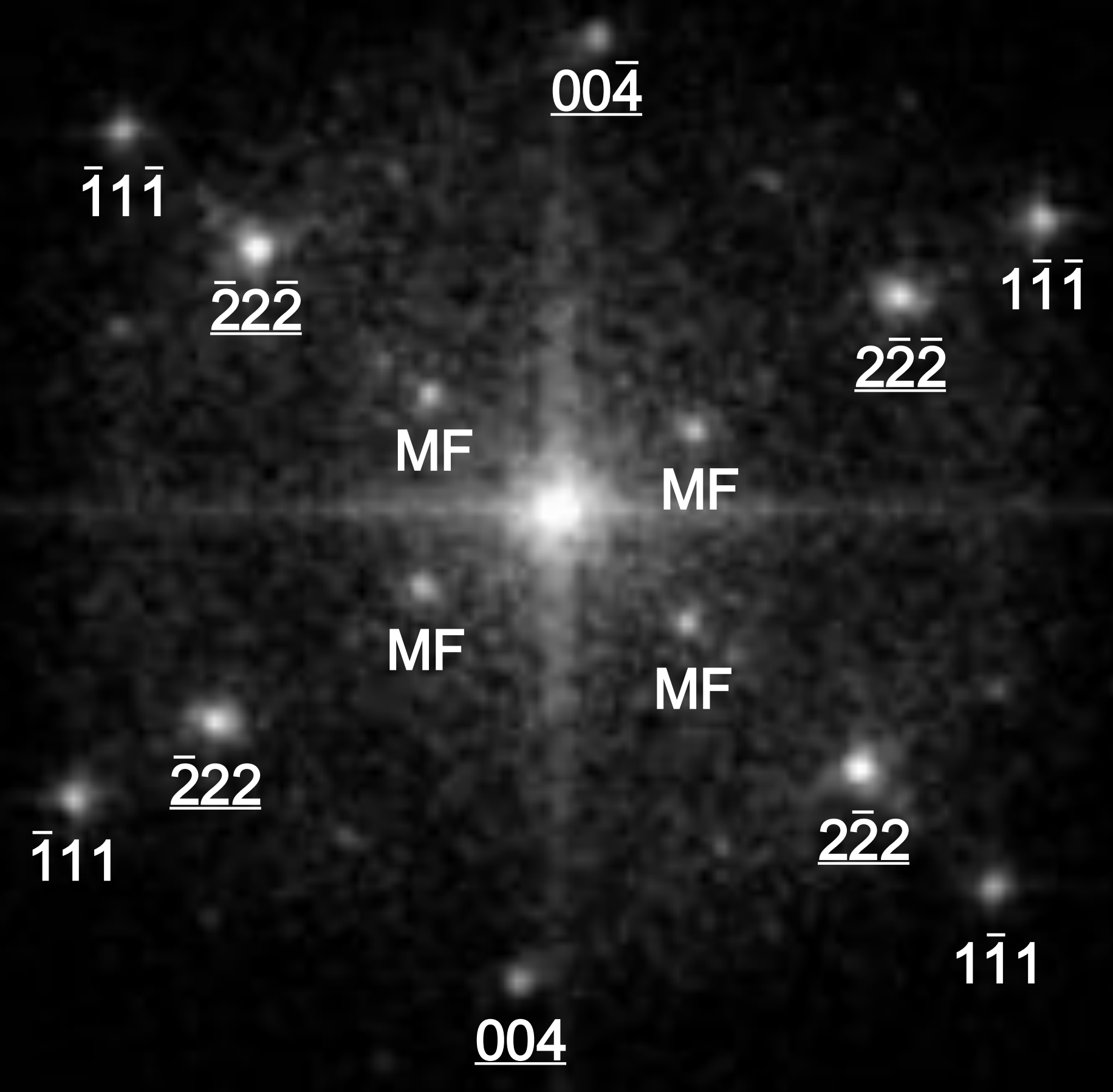

Matrix

Particle

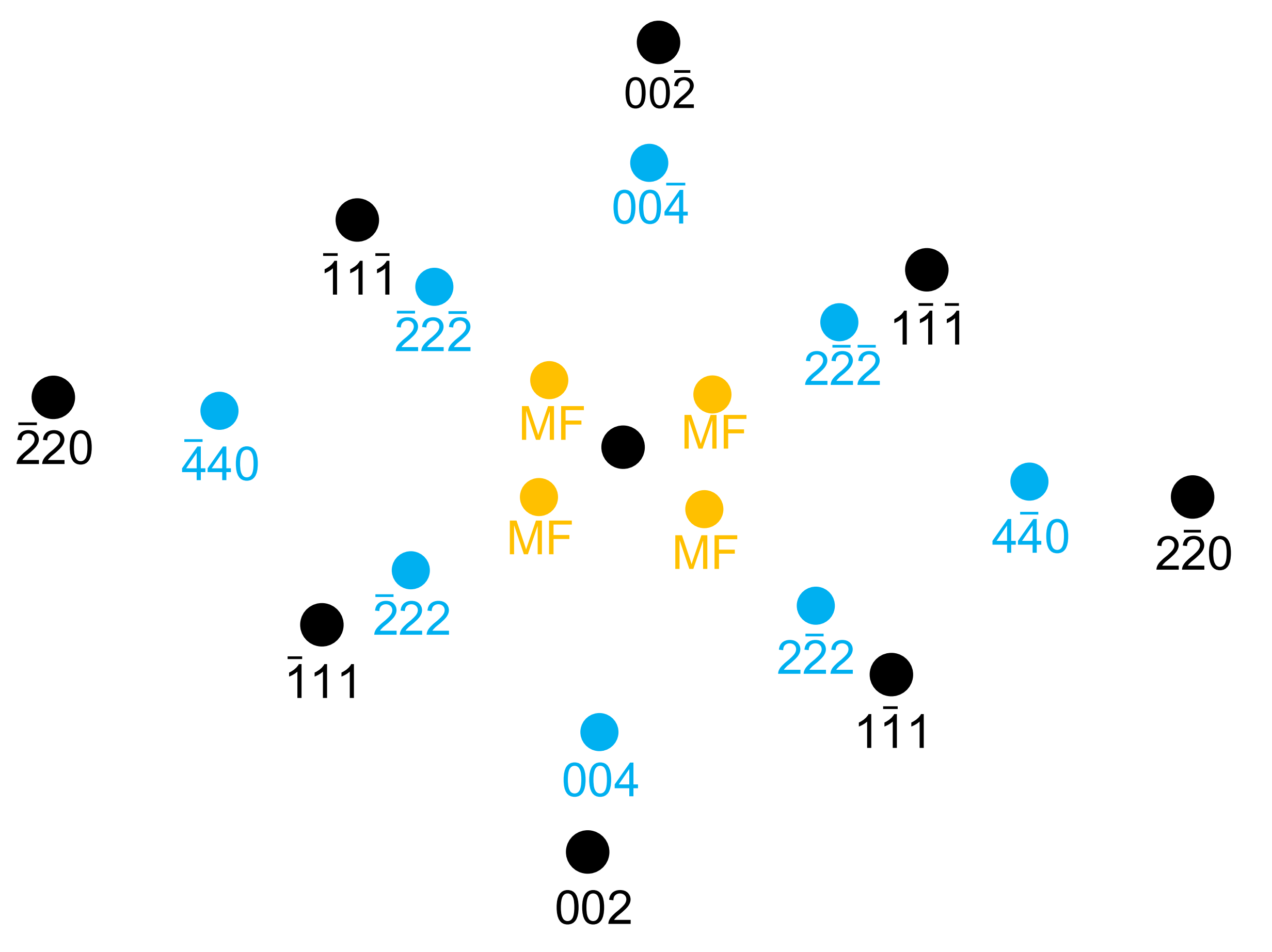




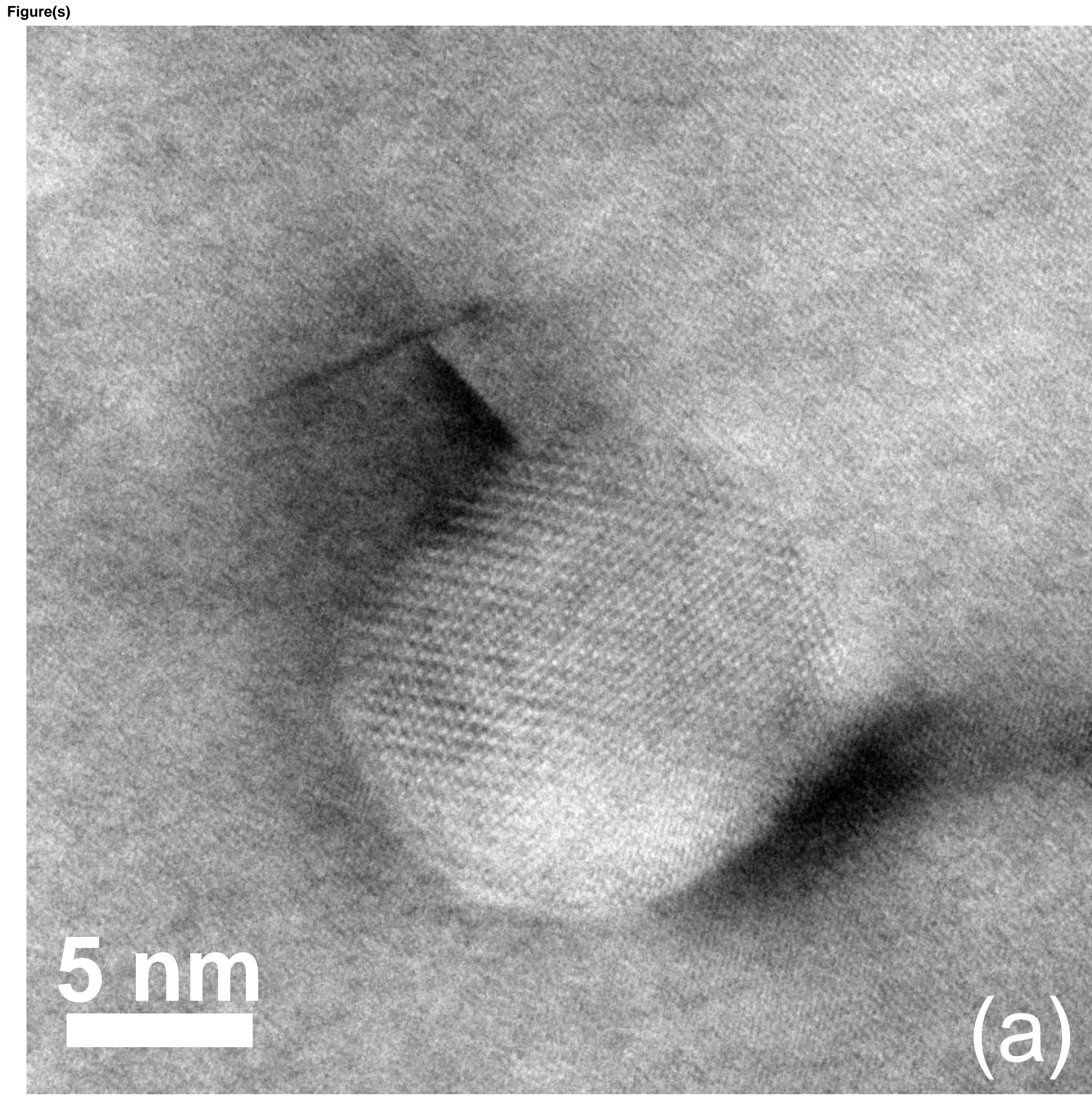

(b)

\section{Matrix \\ Particle}

Matrix

Particle

$2 \overline{2} 0$

\section{$1 \overline{1}$}

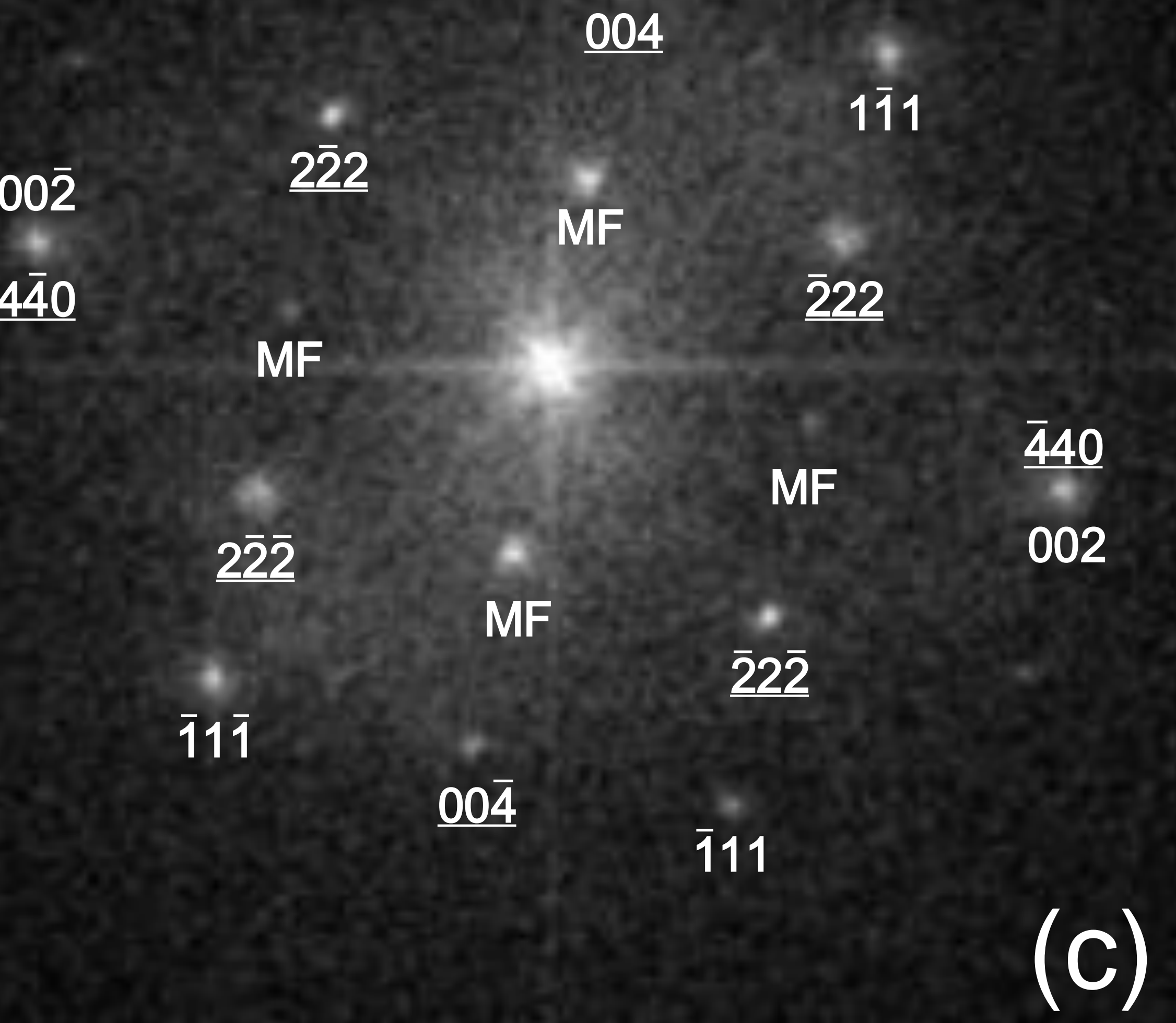

$1 \overline{1} \quad 004$

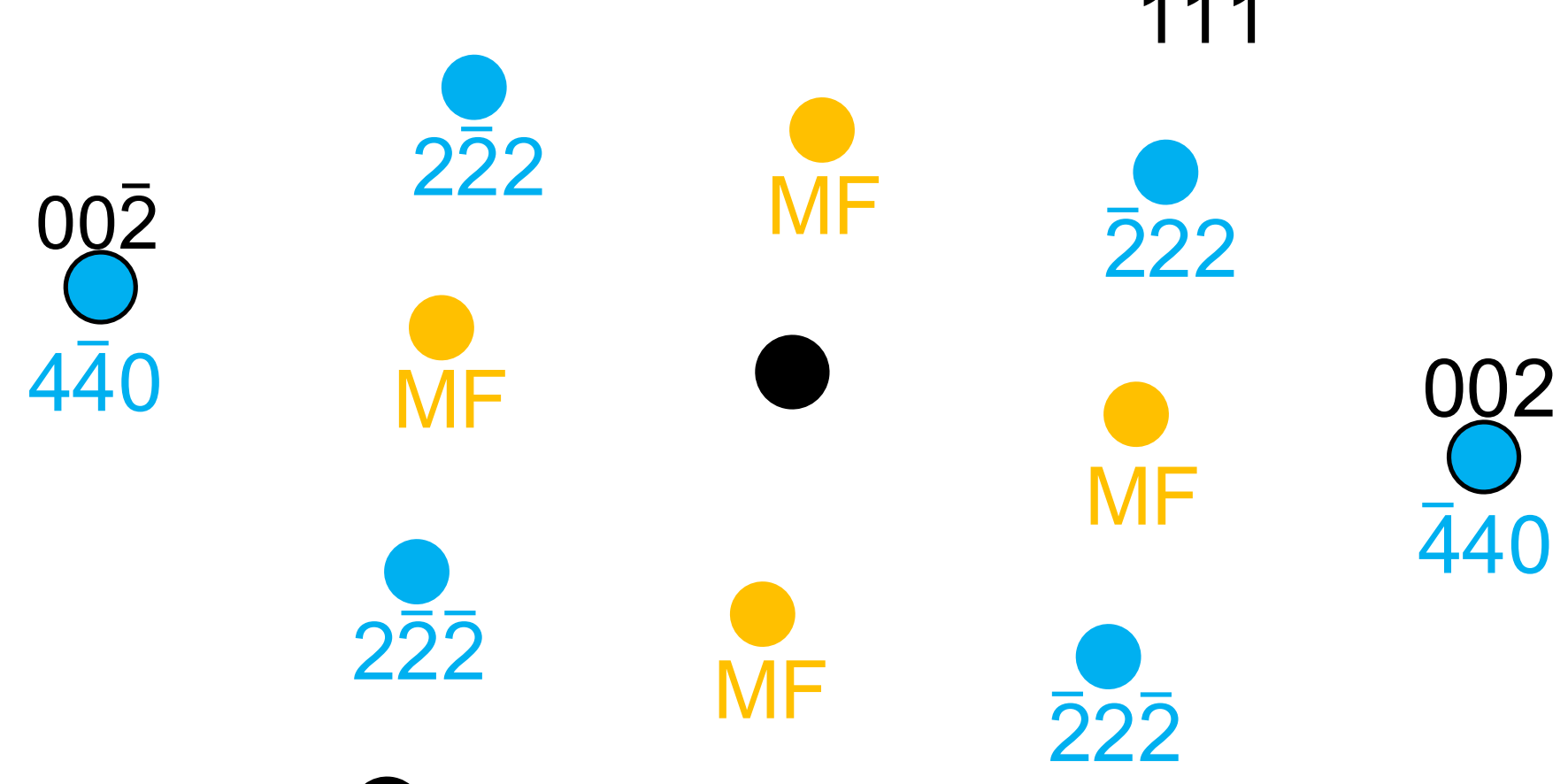

$\stackrel{11 \overline{1}}{00 \overline{4}} \quad \overline{111}$ $\overbrace{440}^{002}$

(d) 

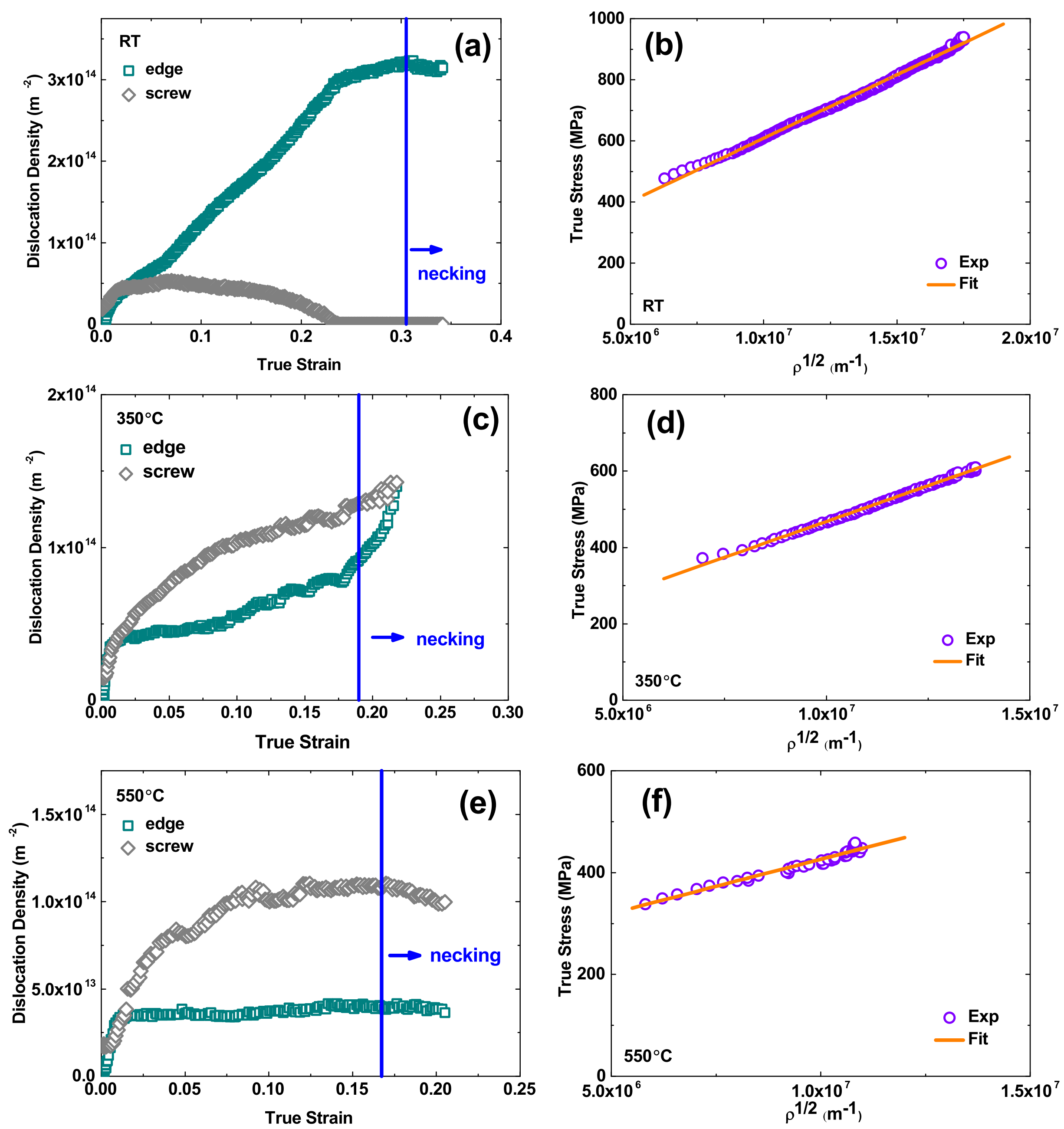


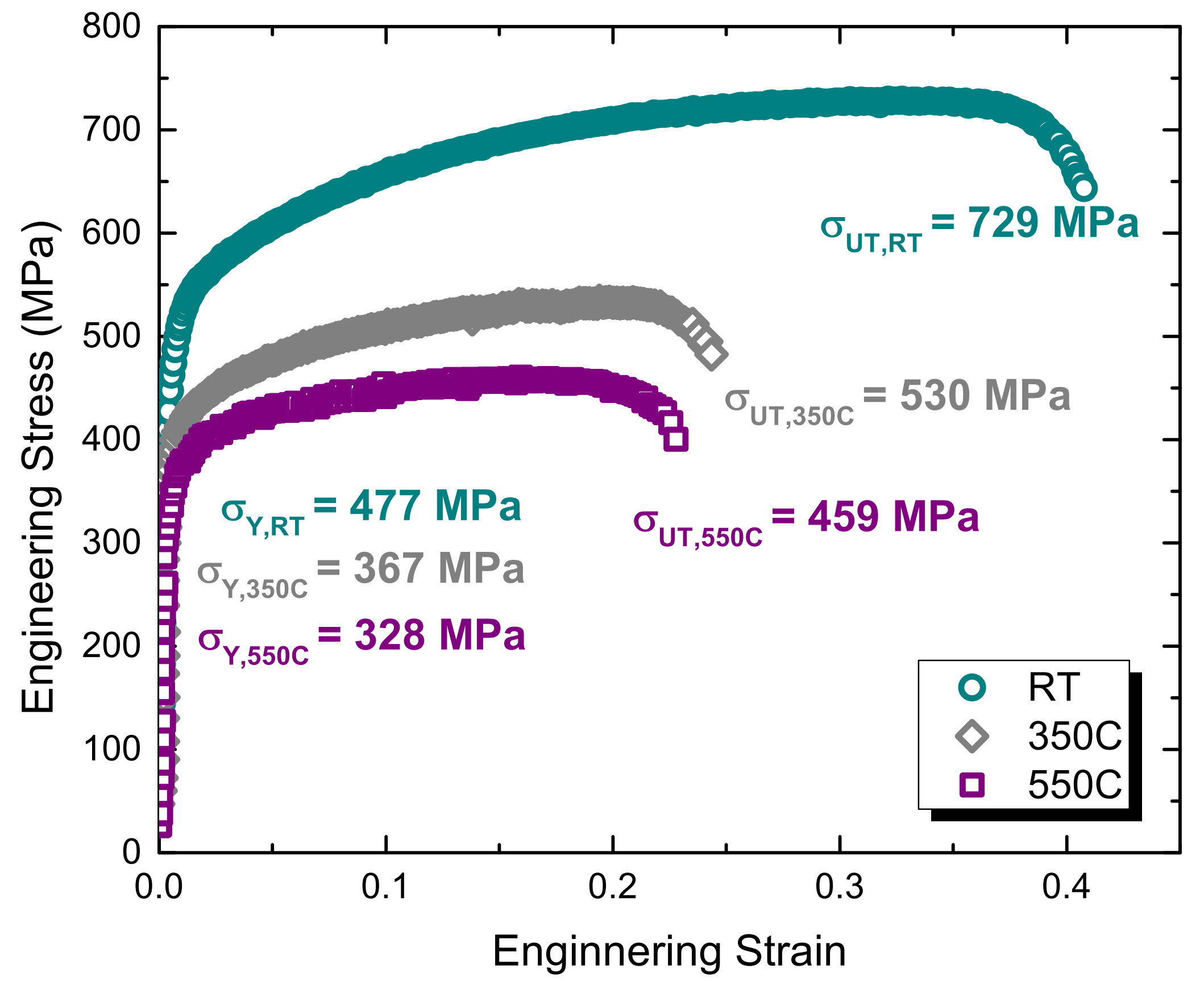




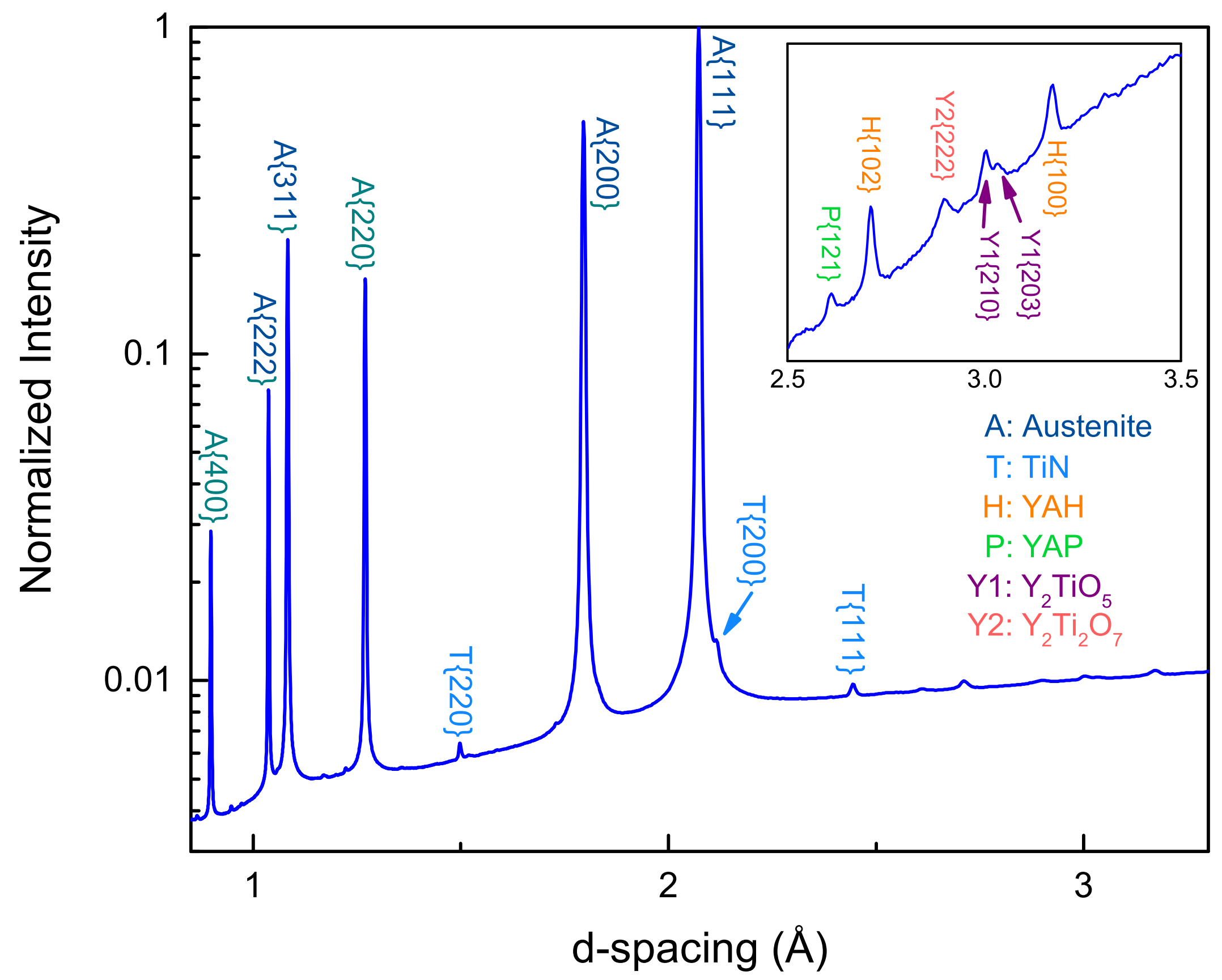



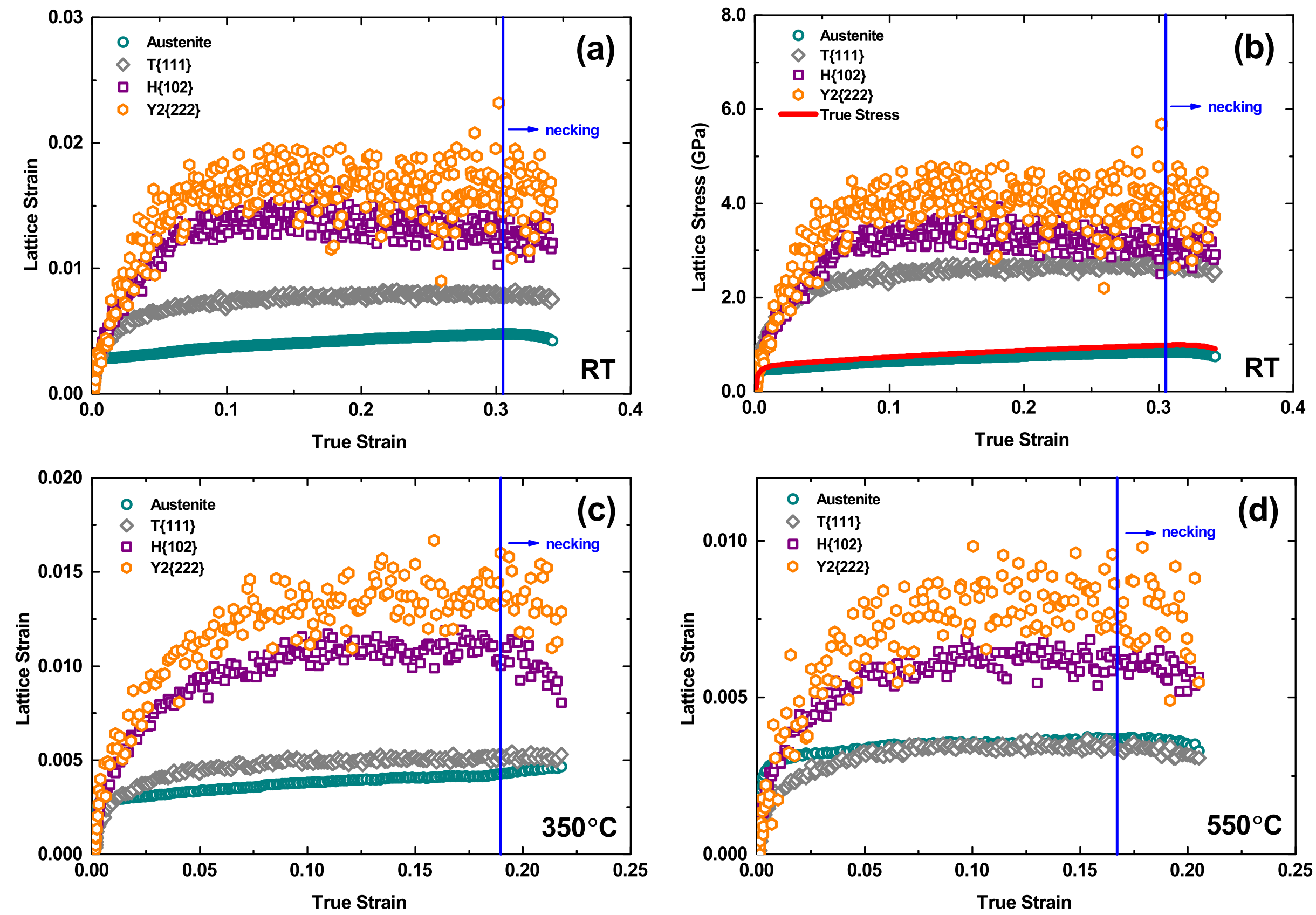


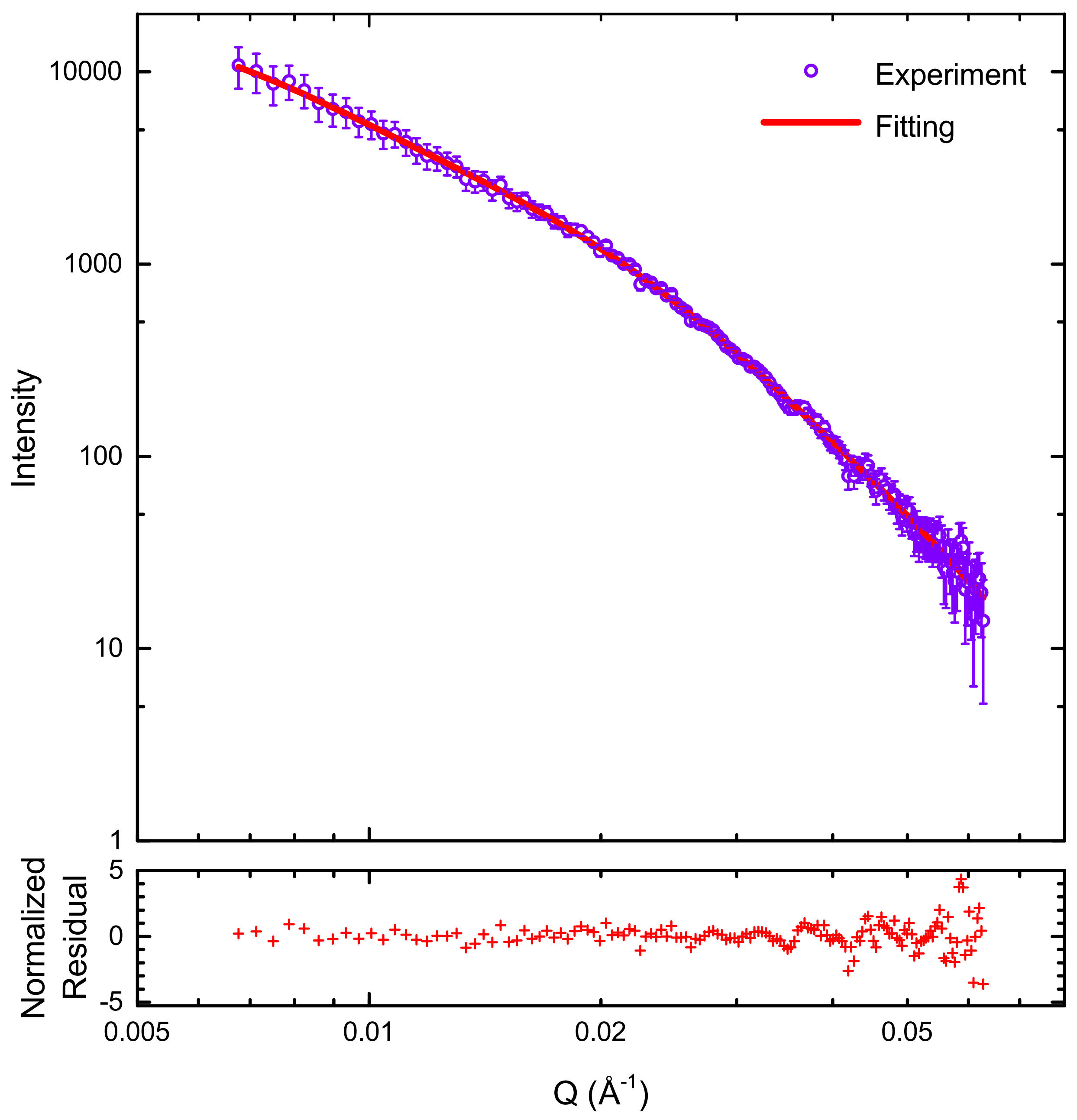




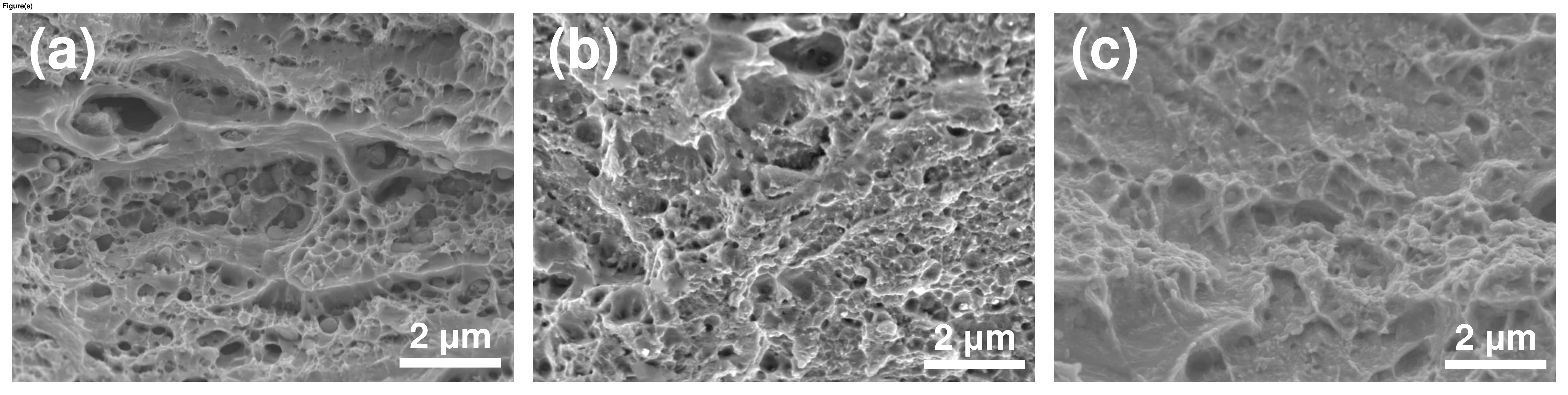




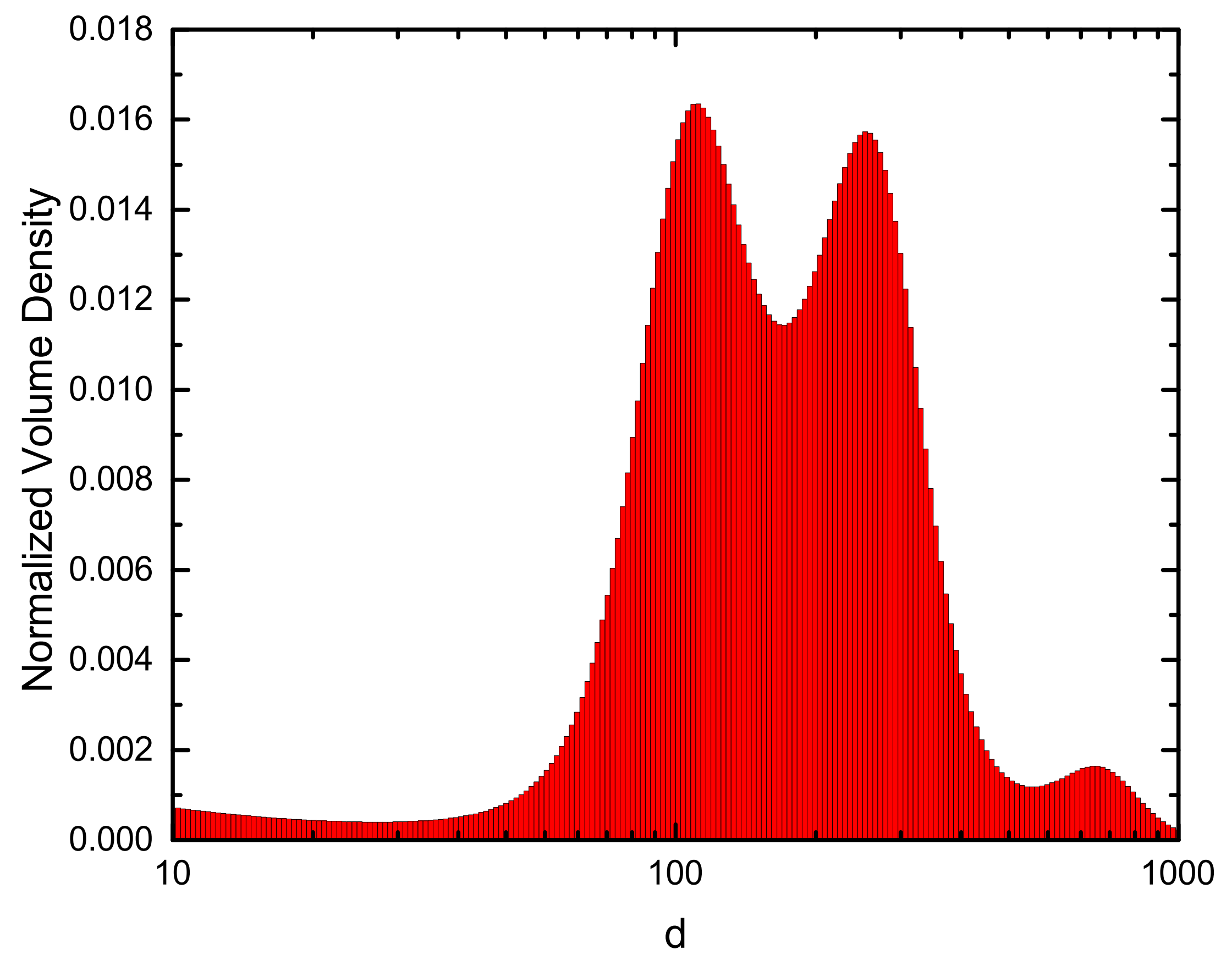




$$
\mathrm{TiN}_{4}^{\rightarrow}
$$

$$
\begin{gathered}
\text { Y-AI-O } \\
Y
\end{gathered}
$$

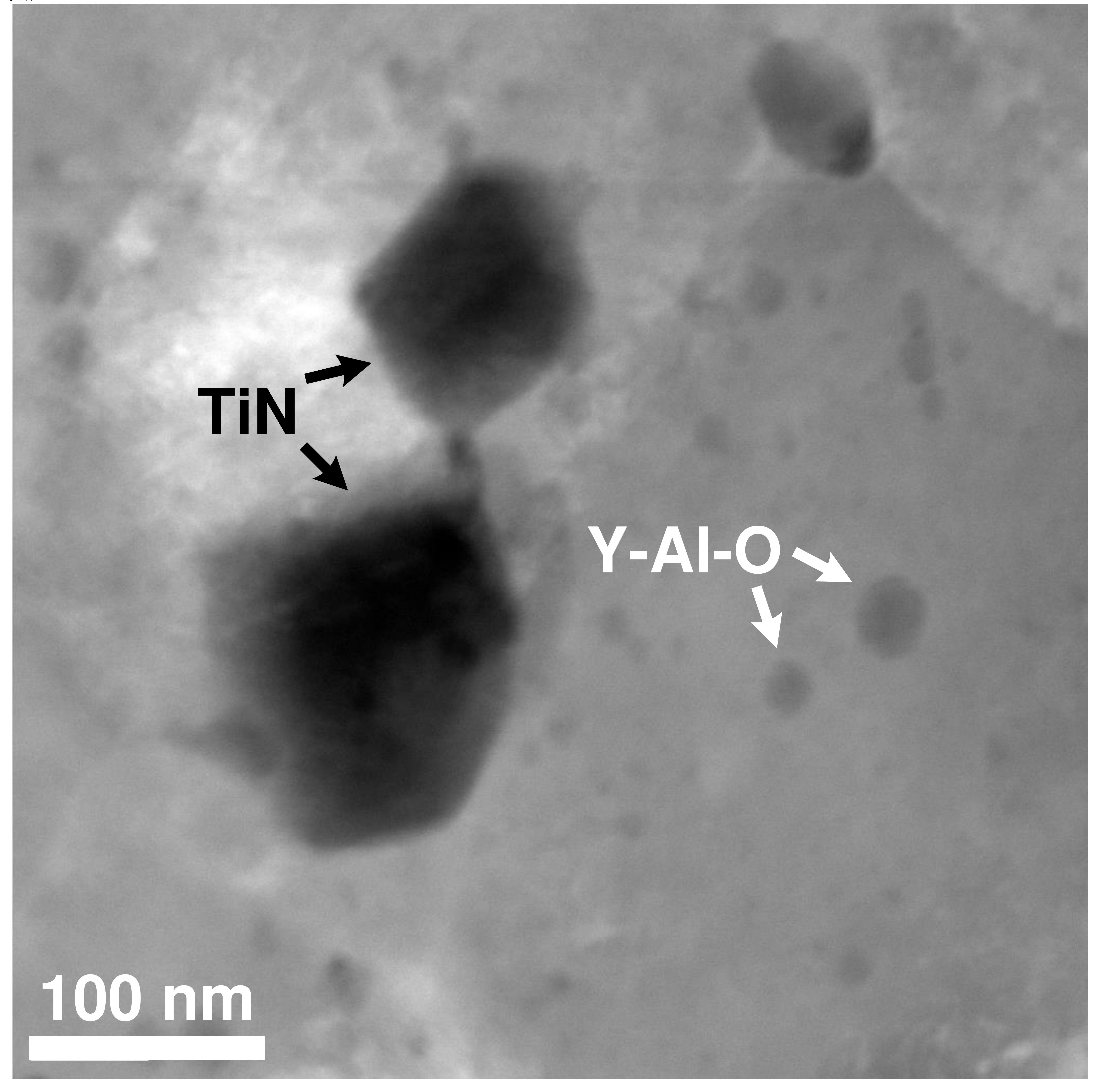




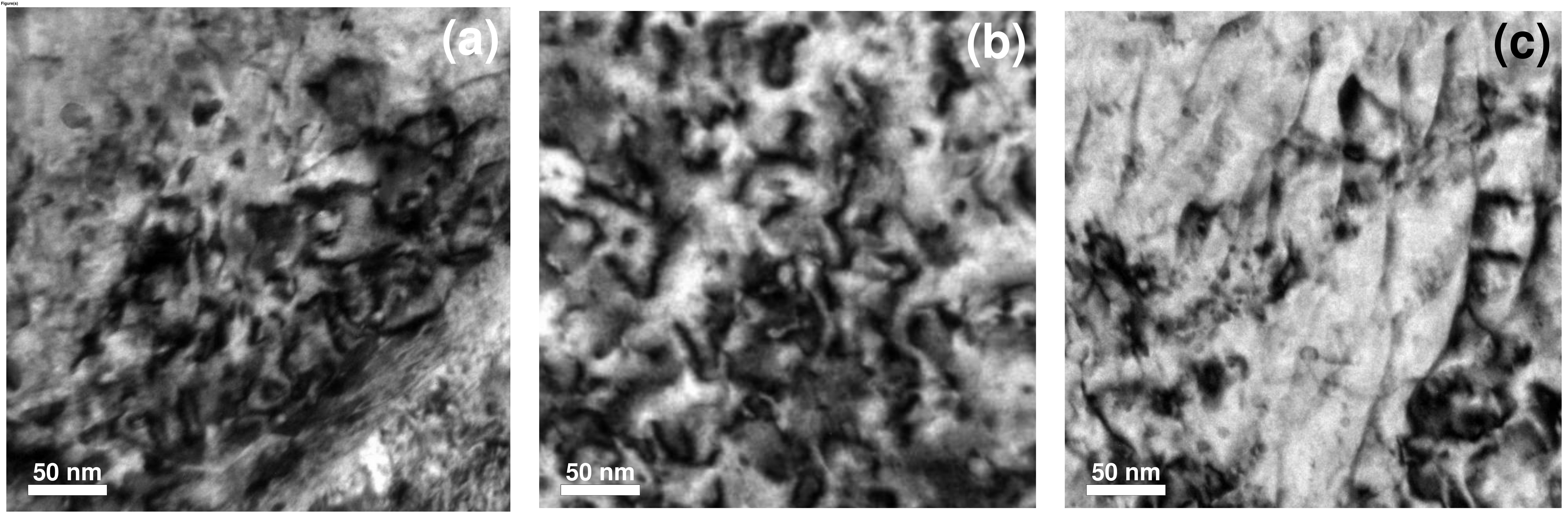

